\title{
Challenges in Moving to Multiscale Battery Models - Where Electrochemistry meets and demands more from Math
}

\author{
Krishna Shah ${ }^{1, *}$, Akshay Subramaniam ${ }^{2, *}$, Lubhani Mishra ${ }^{1}$, Taejin Jang ${ }^{3, *}$, Martin Z. Bazant ${ }^{4}$, \\ Richard D. Braatz ${ }^{4}$, Venkat R. Subramanian ${ }^{1,3, * *, z}$ \\ ${ }^{1}$ Department of Mechanical Engineering, Texas Materials Institute, The University of Texas at Austin, \\ Austin, Texas 78712, USA \\ ${ }^{2}$ Department of Chemical Engineering, University of Washington, Seattle, Washington 98195, USA \\ ${ }^{3}$ Materials Science and Engineering Program, Texas Materials Institute, The University of Texas at \\ Austin, Austin, Texas 78712, USA \\ ${ }^{4}$ Department of Chemical Engineering, Massachusetts Institute of Technology, Cambridge, Massachusetts \\ 02139, USA
}

*Electrochemical Society Student Member

** Electrochemical Society Fellow

${ }^{z}$ E-mail:venkat.subramanian@utexas.edu 


\begin{abstract}
There has been significant recent interest in studying multiscale characteristics of current and next-generation batteries, including lithium-metal and lithium-sulfur batteries. Multiple studies have conveyed the importance of microscale effects, pressure effects, and morphology changes. Advances in computing power make researchers believe that the detailed multiscale models can be efficiently simulated to arrive at the insights for the degradation and performance loss; however, this is not true and special attention needs to be paid to local singularities, boundary layers, moving boundaries, etc. This article presents 2D examples that illustrate the importance of grid convergence studies, provides well-defined detailed models to test the efficiency of numerical schemes, and discusses the associated simulation challenges. This article also provides perspective on important numerical aspects for robustness and efficiency, and recommendations on the possible best practices for studies involving multiscale modeling.
\end{abstract}

Notes: This article has been published as an Editor's Choice Perspective article in the Journal of Electrochemical Society (DOI: https://doi.org/10.1149/1945-7111/abb37b). Details on the analytical solution using conformal mapping technique for Model 1, additional models as Models $8 \boldsymbol{a}$ and $\boldsymbol{8 b}$, Figures 1, 2 and 3, and the text in green font color provided in this version are for addressing comments from the reviewers and to give additional context/details wherever needed. Some of these are not included in the journal article due to the restriction on the word count. 


\section{Introduction}

Though porous electrode pseudo-two-dimensional (p2D) models have been the standard for the study, analysis, and design (and recently control) of lithium-ion batteries, the second dimension (parallel to the current collector) is becoming important for the next-generation batteries. ${ }^{1}$ This is particularly true when studying uneven lithium metal deposition on the anode surface in a lithium metal battery, which leads to dendrite formation. ${ }^{2,3}$ Many numerical methods have been used to simulate multiscale battery models, including finite difference, finite volume, finite element, phase-field, and level-set methods. A typical assumption is that a brute force approach with a large number of nodes/elements will help resolve the physics to an acceptable accuracy. In this work, we describe and provide well-defined detailed two-dimensional models of particular interest when studying lithium metal anodes for next-generation batteries. We first study two linear steady-state problems applicable only under special circumstances but with some key features relevant for battery models. We perform detailed convergence analysis on these models, and demonstrate that the finite element method - a commonly used method to simulate battery models in commercial packages - is unable to solve these relatively simple problems to machine precision. Later, we add mechanisms and physical phenomena to these simple models and provide well-defined models of interest in the context of the lithium metal anode. We discuss numerical challenges in simulating these detailed models. Finally, we share our perspective on the need to pay attention to relevant numerical details associated with the simulation.

\section{Current status}

\section{Motivating examples - Two-dimensional steady-state current-potential distribution}

For demonstration purposes, two simple steady-state problems are considered, one with primary current distribution and the other with secondary current distribution. As shown in Figure 
1, a two-dimensional square domain $\left(\mathrm{L}_{\mathrm{x}}=\mathrm{L}_{\mathrm{y}}\right)$ is considered for both problems. The partial differential equation (PDE) and required boundary conditions for these two problems are given in Models 1 and 2.

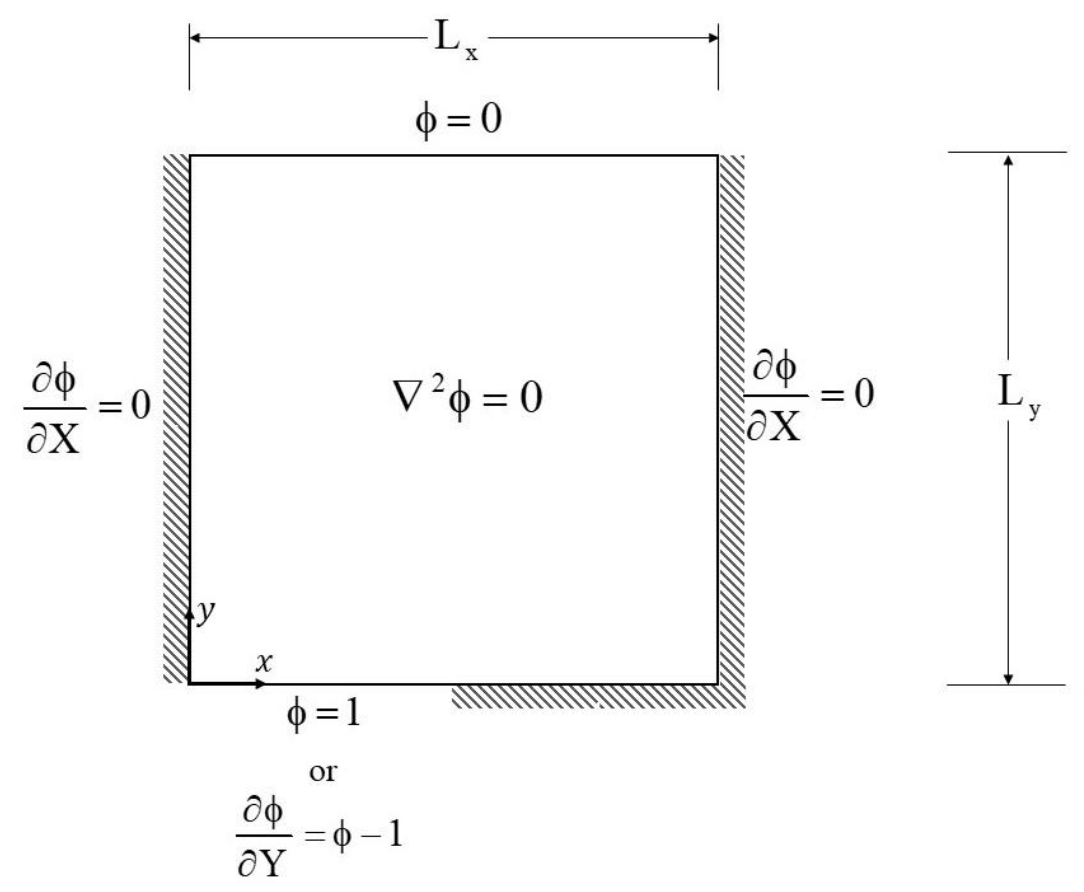

Figure 1. Schematic of two-dimensional problem with primary/secondary current distribution at anode/separator interface.

\section{Model 1}

$$
\begin{aligned}
& \frac{\partial}{\partial X}\left(\frac{\partial \phi}{\partial X}\right)+\frac{\partial}{\partial Y}\left(\frac{\partial \phi}{\partial Y}\right)=0 \\
& \frac{\partial \phi}{\partial X}=0 \quad \text { at } \mathrm{X}=0,1 \\
& \phi=0 \quad \text { at } \mathrm{Y}=1 \\
& \phi=1 \quad \text { at } \mathrm{Y}=0,0 \leq \mathrm{X} \leq 0.5 \\
& \frac{\partial \phi}{\partial \mathrm{Y}}=0 \quad \text { at } \mathrm{Y}=0,0.5<\mathrm{X} \leq 1
\end{aligned}
$$




\section{Model 2}

$$
\begin{aligned}
& \frac{\partial}{\partial X}\left(\frac{\partial \phi}{\partial X}\right)+\frac{\partial}{\partial Y}\left(\frac{\partial \phi}{\partial Y}\right)=0 \\
& \frac{\partial \phi}{\partial X}=0 \text { at } \mathrm{X}=0,1 \\
& \phi=0 \text { at } \mathrm{Y}=1 \\
& \frac{\partial \phi}{\partial \mathrm{Y}}=\phi-1 \text { at } \mathrm{Y}=0,0 \leq \mathrm{X} \leq 0.5 \\
& \frac{\partial \phi}{\partial \mathrm{Y}}=0 \text { at } \mathrm{Y}=0,0.5<\mathrm{X} \leq 1
\end{aligned}
$$

Models 1 and 2 are limited to finding the ohmic drop across the separator domain in the absence of concentration gradients. The potential field in the liquid phase and associated current density distributions (primary and secondary) are typically obtained by solving Laplace's equation. ${ }^{4,5,6,7}$ Mass transfer-limited current distribution at steady state for binary electrolyte also results in Laplace's equation. ${ }^{4}$ In general, battery models involve mass transfer in liquid and solid phases in porous electrodes, typically using concentrated or dilute solution theories, which results in PDEs as a function of space (x, y) and time (t).

These models consider primary or secondary current distribution at $\mathrm{Y}=0,0 \leq \mathrm{X} \leq 0.5$, indicating that only a part of the separator is in contact with the anode as shown in Figure 1 . This singularity at $\mathrm{X}=0.5, \mathrm{Y}=0$, which is the anode/insulator interface, is a key aspect in simulating lithium metal batteries. The Dirichlet condition is applied at $\mathrm{Y}=1$, which can be viewed as the bulk condition or setting the cathode potential to a particular value. The rest of the sides of the domain are treated as walls with zero flux. 
Large format batteries typically involve multiple such configurations, and when two dimensions are considered, at least one point at the boundary will have an electrode/insulator interface or an interface of materials with different properties leading to a singularity.

\subsection{Numerical method - FEM}

The Finite Element Method (FEM) is a widely used discretization method for 2D models. FEM in the weak form is based on a variational formulation which does not require flux continuity at the interface between two elements.

The underlying mathematical formulation consists of the weak form being applied to each element:

$$
\int_{y=-b}^{y=b} \int_{x=-a}^{x=a} \frac{\partial W}{\partial x} \frac{\partial \phi}{\partial x} d x d y+\int_{y=-b}^{y=b} \int_{x=-a}^{x=a} \frac{\partial W}{\partial y} \frac{\partial \phi}{\partial y} d x d y=\int_{\Gamma} W\left(\frac{\partial \phi}{\partial x} n_{x}+\frac{\partial \phi}{\partial y} n_{y}\right) d x d y
$$

where

$$
\phi=\sum_{i=1}^{m} N_{i} \phi_{i}
$$

and the weight function is taken to be $\mathrm{W}=\phi$ and $\mathrm{N}_{\mathrm{i}}$ are the shape functions. Bilinear shape functions are given by

$$
\begin{aligned}
& \mathrm{N}_{1}=\frac{1}{4}\left(1-\frac{\mathrm{x}}{\mathrm{a}}\right)\left(1-\frac{\mathrm{y}}{\mathrm{b}}\right) ; \mathrm{N}_{2}=\frac{1}{4}\left(1+\frac{\mathrm{x}}{\mathrm{a}}\right)\left(1-\frac{\mathrm{y}}{\mathrm{b}}\right) \\
& \mathrm{N}_{3}=\frac{1}{4}\left(1+\frac{\mathrm{x}}{\mathrm{a}}\right)\left(1+\frac{\mathrm{y}}{\mathrm{b}}\right) ; \mathrm{N}_{4}=\frac{1}{4}\left(1-\frac{\mathrm{x}}{\mathrm{a}}\right)\left(1+\frac{\mathrm{y}}{\mathrm{b}}\right)
\end{aligned}
$$

where $\mathrm{a}$ and $\mathrm{b}$ are half of the element sizes in the $\mathrm{x}$ and $\mathrm{y}$ directions, respectively. Here, a local coordinate system is applicable at the element level which is different from the global coordinate 
system for the domain shown in Figure 1. This formulation is applied to each element resulting in the linear matrix equation

$$
\mathrm{A} \Phi=\mathrm{B}
$$

where $\Phi$ is a vector containing the discretized values of $\phi$ to be solved at each node in the domain.

Some of the different types of shape functions that can be used are bilinear, biquadratic, and bicubic. The choice of the shape function greatly affects the order of convergence and the number of equations to be solved for a given number of elements. The coefficient matrix A in Eq. (6) is sparse, and linear solvers which exploit sparsity are typically used for efficiency. Both Models 1 and 2 are solved using in-house FEM codes validated with COMSOL Multiphysics 5.4, a FEMbased simulation package used to conduct 2D and 3D modeling studies by many researchers for electrochemical systems. The results between the two are found to match up to 12 digits after the decimal, which is done to ensure that the findings from the subsequent analysis can be attributed to the numerical method, and not to the implementation of the method or programming environment/tool used.

\subsection{Error analysis - Primary current distribution}

There are different approaches to quantify the numerical accuracy and convergence of the FEM. ${ }^{8}$ When this problem was first attempted with in-house FEM codes, and later confirmed with COMSOL Multiphysics 5.4, the obtained results seemed to oscillate for the $4^{\text {th }}$ or $5^{\text {th }}$ digit after the decimal. Having a very fine mesh near the singularity helps in recovering the expected order of convergence away from the singularity. However, our interest lies in the values of the variables at the electrode surface where the singularity exists. A simple error analysis is performed by comparing the numerical solutions with the analytical solution obtained using conformal mapping 
technique. ${ }^{9,10}$ Results from the error analysis are given in Table 1 . The solution obtained in the transformed coordinates using conformal mapping, along with the solution procedure, is given below. A schematic illustrating the transformations is given in Figure 2.

First the original square domain in the $\mathrm{Z}=\mathrm{X}+\mathrm{IY}$ coordinate system is transformed to a line from $-\infty$ to $+\infty$ in the w coordinate system using

$$
\frac{\mathrm{dZ}}{\mathrm{dw}}=\frac{-\mathrm{I} \mathrm{K}[1]}{\sqrt{\mathrm{w}} \sqrt{\mathrm{w}-1} \sqrt{\mathrm{w}-1-\mathrm{a}} \sqrt{\mathrm{w}-2-\mathrm{a}}}
$$

where $\mathrm{K}[1]$ and a are solved using the conditions $\mathrm{w}=1$ when $\mathrm{Z}=1+0 \mathrm{I}$ and $\mathrm{w}=1+\mathrm{a}$ when $\mathrm{Z}=1+1 \mathrm{I}$, corresponding to $\mathrm{X}=1, \mathrm{Y}=0$ and $\mathrm{X}=1, \mathrm{Y}=1$ in the original geometry, respectively. The value of a is found to be $\sqrt{2}-1$. Now $w$ is mapped to $\mathrm{Z} 2=\mathrm{X} 2+\mathrm{IY} 2$ using the transformation,

$$
\frac{\mathrm{dZ2}}{\mathrm{dw}}=\frac{-\mathrm{IK}[2]}{\sqrt{\mathrm{w}} \sqrt{\mathrm{w}-\frac{1}{\sqrt{2}} \sqrt{\mathrm{w}-1-\mathrm{a}} \sqrt{\mathrm{w}-2-\mathrm{a}}}}
$$

where $\mathrm{Z} 2=1+0$ I when $\mathrm{w}=\frac{1}{\sqrt{2}}$ is used to determine $\mathrm{K}[2]$, and $\mathrm{Z} 2=1+\mathrm{H} \mathrm{I}$ when $\mathrm{w}=1+\mathrm{a}$ is used to obtain $\mathrm{H}$. The final solution in the $\mathrm{Z} 2$ coordinate system is

$$
\phi=1-\frac{\text { EllipticK }\left(\frac{1}{\sqrt{2+\sqrt{2}}}\right) Y 2}{\text { EllipticK }\left(\sqrt{\frac{\sqrt{2}+1}{2+\sqrt{2}}}\right)}
$$




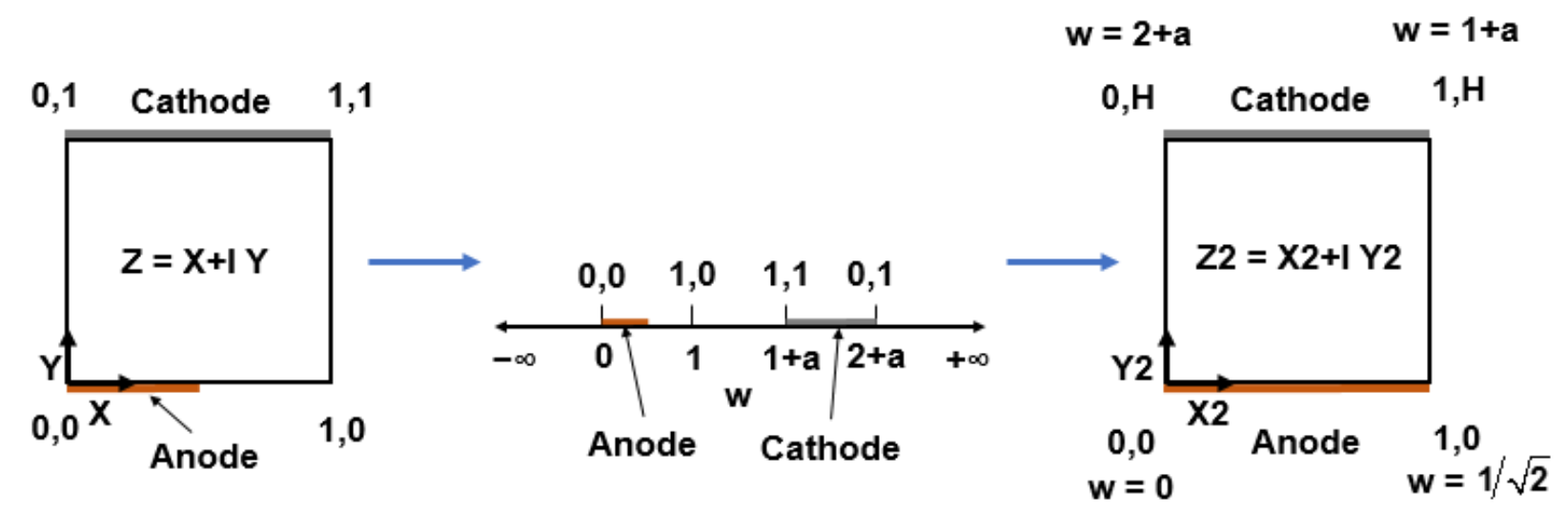

Figure 2. Schematic showing transformations of the computation domain for Model 1 using conformal mapping technique. For the above transformation, a is determined to be $\sqrt{2}-1$. 


\begin{tabular}{|c|c|c|c|c|c|c|c|c|c|c|}
\hline \multirow{3}{*}{$\begin{array}{c}\text { Variable of } \\
\text { interest }\end{array}$} & \multirow{3}{*}{$\begin{array}{c}\text { Element } \\
\text { size } \\
\mathrm{h}_{\mathrm{x}}=\mathrm{h}_{\mathrm{y}}=\mathrm{h}\end{array}$} & \multicolumn{3}{|c|}{ Bilinear } & \multicolumn{3}{|c|}{ Biquadratic } & \multicolumn{3}{|c|}{ Bicubic } \\
\hline & & \multirow[t]{2}{*}{$\begin{array}{c}\text { Numerical } \\
\text { solution }\end{array}$} & \multirow{2}{*}{$\begin{array}{c}\text { Error } \\
E_{a}= \\
\text { |Numerical } \\
\text { solution - } \\
\text { Analytical } \\
\text { solution* } \\
\end{array}$} & \multirow{2}{*}{ 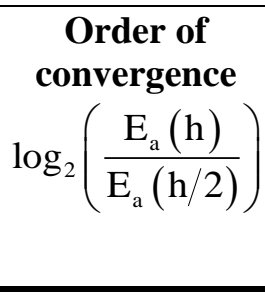 } & \multirow[t]{2}{*}{$\begin{array}{c}\text { Numerical } \\
\text { solution }\end{array}$} & \multirow{2}{*}{$\begin{array}{c}\text { Error } \\
E_{a}= \\
\mid \text { Numerical } \\
\text { solution - } \\
\text { Analytical } \\
\text { solution* } \\
\end{array}$} & $\begin{array}{c}\text { Order of } \\
\text { convergence }\end{array}$ & \multirow[t]{2}{*}{$\begin{array}{c}\text { Numerical } \\
\text { solution }\end{array}$} & \multirow{2}{*}{$\begin{array}{c}\text { Error } \\
E_{a}= \\
\mid \text { Numerical } \\
\text { solution - } \\
\text { Analytical } \\
\text { solution }{ }^{*} \mid \\
\end{array}$} & \multirow{2}{*}{$\begin{array}{c}\text { Order of } \\
\text { convergence } \\
\log _{2}\left(\frac{E_{a}(h)}{E_{a}(h / 2)}\right.\end{array}$} \\
\hline & & & & & & & $\log _{2}\left(\frac{E_{a}(h)}{E_{a}(h / 2)}\right)$ & & & \\
\hline \multirow{5}{*}{$\frac{\partial \phi}{\partial Y}(0,0)$} & $1 / 100$ & -1.1594 & $1.87896 \mathrm{E}-03$ & 1.0351 & -1.16076 & 5.51613E-04 & 0.9698 & -1.16102 & $2.92713 \mathrm{E}-04$ & 1.0000 \\
\hline & $1 / 200$ & -1.1604 & $9.16912 \mathrm{E}-04$ & 1.0181 & -1.16103 & $2.81638 \mathrm{E}-04$ & 0.9851 & -1.16117 & $1.46358 \mathrm{E}-04$ & 1.0000 \\
\hline & $1 / 400$ & -1.1609 & $4.52738 \mathrm{E}-04$ & 1.0092 & -1.16117 & $1.42284 \mathrm{E}-04$ & 0.9925 & -1.16124 & 7.31788E-05 & 1.0000 \\
\hline & $1 / 800$ & -1.1611 & $2.24930 \mathrm{E}-04$ & 1.0046 & -1.16124 & 7.15124E-05 & 0.9964 & -1.16127 & 3.65899E-05 & 0.9999 \\
\hline & $1 / 1600$ & -1.1612 & $1.12104 \mathrm{E}-04$ & - & -1.16128 & $3.58460 \mathrm{E}-05$ & - & -1.16129 & $1.82967 \mathrm{E}-05$ & - \\
\hline \multirow{5}{*}{$\frac{\partial \phi}{\partial Y}(0.25,0)$} & $1 / 100$ & -1.2706 & $3.89979 \mathrm{E}-03$ & 1.0780 & -1.2734 & $1.03682 \mathrm{E}-03$ & 1.0183 & -1.27393 & $5.43035 \mathrm{E}-04$ & 1.1505 \\
\hline & $1 / 200$ & -1.2726 & $1.84729 \mathrm{E}-03$ & 1.0742 & -1.2740 & $5.11870 \mathrm{E}-04$ & 1.1284 & -1.27423 & $2.44618 \mathrm{E}-04$ & 1.3586 \\
\hline & $1 / 400$ & -1.2736 & $8.77329 \mathrm{E}-04$ & 1.1087 & -1.2742 & $2.34148 \mathrm{E}-04$ & 1.3566 & -1.27438 & $9.53903 \mathrm{E}-05$ & 2.1989 \\
\hline & $1 / 800$ & -1.2741 & $4.06842 \mathrm{E}-04$ & 1.2149 & -1.2744 & 9.14318E-05 & 2.2574 & -1.27445 & $2.07759 \mathrm{E}-05$ & 0.3298 \\
\hline & $1 / 1600$ & -1.2743 & $1.75269 \mathrm{E}-04$ & - & -1.2745 & $1.91234 \mathrm{E}-05$ & - & -1.27449 & $1.65299 \mathrm{E}-05$ & - \\
\hline \multirow{5}{*}{$\phi(1,0)$} & $1 / 100$ & 0.5431 & $1.57930 \mathrm{E}-03$ & 0.9957 & 0.54199 & $5.10919 \mathrm{E}-04$ & 1.0000 & 0.54174 & $2.60089 \mathrm{E}-04$ & 1.0000 \\
\hline & $1 / 200$ & 0.5423 & 7.91982E-04 & 0.9979 & 0.54173 & $2.55457 \mathrm{E}-04$ & 1.0000 & 0.54161 & $1.30044 \mathrm{E}-04$ & 1.0000 \\
\hline & $1 / 400$ & 0.5419 & $3.96571 \mathrm{E}-04$ & 0.9989 & 0.54160 & $1.27728 \mathrm{E}-04$ & 1.0000 & 0.54154 & $6.50218 \mathrm{E}-05$ & 1.0000 \\
\hline & $1 / 800$ & 0.5417 & $1.98430 \mathrm{E}-04$ & 0.9995 & 0.54154 & 6.38633E-05 & 0.9999 & 0.54151 & $3.25110 \mathrm{E}-05$ & 1.0000 \\
\hline & $1 / 1600$ & 0.5416 & $9.92512 \mathrm{E}-05$ & - & 0.54151 & $3.19331 \mathrm{E}-05$ & - & 0.54149 & $1.62561 \mathrm{E}-05$ & - \\
\hline \multirow{5}{*}{$\begin{array}{c}\text { Average } \\
\text { current } \\
\text { density at } \\
Y=0 \\
\frac{1}{0.5} \int_{X=0}^{X=0.5} \frac{\partial \phi}{\partial Y} \mathrm{dX}\end{array}$} & $1 / 100$ & -1.532 & $1.24497 \mathrm{E}-01$ & 0.4095 & -1.589 & $6.77950 \mathrm{E}-02$ & 0.3515 & -1.605 & $5.19807 \mathrm{E}-02$ & 0.3115 \\
\hline & $1 / 200$ & -1.563 & $9.37319 \mathrm{E}-02$ & 0.3878 & -1.603 & 5.31338E-02 & 0.3156 & -1.615 & 4.18864E-02 & 0.2713 \\
\hline & $1 / 400$ & -1.585 & $7.16365 \mathrm{E}-02$ & 0.3591 & -1.614 & 4.26951E-02 & 0.2754 & -1.622 & $3.47060 \mathrm{E}-02$ & 0.2293 \\
\hline & $1 / 800$ & -1.601 & $5.58507 \mathrm{E}-02$ & 0.3242 & -1.621 & $3.52752 \mathrm{E}-02$ & 0.2333 & -1.627 & $2.96067 \mathrm{E}-02$ & 0.1880 \\
\hline & $1 / 1600$ & -1.612 & 4.46105E-02 & - & -1.626 & $3.00082 \mathrm{E}-02$ & - & -1.631 & $2.59898 \mathrm{E}-02$ & - \\
\hline & luti & $\frac{\partial \phi}{\partial Y}(0,0)$ & & $\frac{\partial \phi}{\partial \mathrm{Y}}(0.25,0)$ & & & & $\left.5 \int_{\mathrm{X}=0}^{\mathrm{X}=0.5} \frac{\partial \phi}{\partial \mathrm{Y}}\right|_{\mathrm{Y}=0}$ & $=-16565076$ & 77779 \\
\hline
\end{tabular}


Observations from Table 1 are

- All the three shape functions provide only first-order convergence, with bilinear shape functions having the advantage of lowest cost. For robust simulations, smaller element size and bilinear shape functions can be used near singularities, and higher order methods with larger element size elsewhere. ${ }^{11}$

- Because of strong singularity, FEM solution converged only to 1 digit after the decimal for the average current density, leading to poor prediction of the ohmic resistance.

Similar conclusions are expected from any numerical method unless mesh adaptivity is used. Fortunately, the error in battery models may be less for secondary current distribution, which is analyzed next.

\subsection{Error analysis - Secondary current distribution}

In this case, the exact solution is not available, and the error analysis is performed by comparing the values by doubling the number of elements in both $\mathrm{x}$ and $\mathrm{y}$ directions. Results are summarized in Table 2. 
Table 2. Error and convergence analysis using different shape functions in FEM for the secondary current distribution (Model 2).

\begin{tabular}{|c|c|c|c|c|c|c|c|c|c|c|}
\hline \multirow{3}{*}{$\begin{array}{c}\text { Variable of } \\
\text { interest }\end{array}$} & \multirow{3}{*}{$\begin{array}{c}\text { Element } \\
\text { size } \\
h_{x}=h_{y}=h\end{array}$} & \multicolumn{3}{|c|}{ Bilinear } & \multicolumn{3}{|c|}{ Biquadratic } & \multicolumn{3}{|c|}{ Bicubic } \\
\hline & & \multirow[t]{2}{*}{$\begin{array}{l}\text { Numerical } \\
\text { solution }\end{array}$} & \multirow{2}{*}{$\begin{array}{c}\text { Error } \\
\mathrm{E}_{\mathrm{r}}= \\
\mid \text { Numerical } \\
\text { solution (h/2) } \\
\text { - Numerical } \\
\text { solution (h) } \mid \\
\end{array}$} & \multirow{2}{*}{$\begin{array}{c}\text { Order of } \\
\text { convergence } \\
\log _{2}\left(\frac{E_{r}(h)}{E_{r}(h / 2)}\right)\end{array}$} & \multirow[t]{2}{*}{$\begin{array}{c}\text { Numerical } \\
\text { solution }\end{array}$} & \multirow{2}{*}{\begin{tabular}{|c|} 
Error \\
$\mathrm{E}_{\mathrm{r}}=$ \\
$\mid$ Numerical \\
solution (h/2) \\
- Numerical \\
solution (h)| \\
\end{tabular}} & $\begin{array}{c}\text { Order of } \\
\text { convergence }\end{array}$ & \multirow[t]{2}{*}{$\begin{array}{l}\text { Numerical } \\
\text { solution }\end{array}$} & \multirow{2}{*}{\begin{tabular}{|c|} 
Error \\
$\mathrm{E}_{\mathrm{r}}=$ \\
$\mid$ Numerical \\
solution (h/2) \\
- Numerical \\
solution (h) \\
\end{tabular}} & $\begin{array}{c}\text { Order of } \\
\text { convergence }\end{array}$ \\
\hline & & & & & & & $\log _{2}\left(\frac{E_{r}(h)}{E_{r}(h / 2)}\right)$ & & & $\log _{2}\left(\frac{E_{r}(h)}{E_{r}(h / 2)}\right.$ \\
\hline \multirow{5}{*}{$\phi(0,0)$} & $1 / 100$ & 0.4137893 & 4.39099E-06 & 1.8792 & 0.41378348 & $1.34207 \mathrm{E}-07$ & 1.9981 & 0.4137833463 & 3.19863E-08 & 2.0033 \\
\hline & $1 / 200$ & 0.4137849 & $1.19365 \mathrm{E}-06$ & 1.8883 & 0.41378335 & $3.35960 \mathrm{E}-08$ & 1.9920 & 0.4137833143 & 7.97813E-09 & 2.0656 \\
\hline & $1 / 400$ & 0.4137837 & 3.22431E-07 & 1.8962 & 0.41378331 & 8.44555E-09 & 2.0690 & 0.4137833063 & \begin{tabular}{|l|}
$1.90590 \mathrm{E}-09$ \\
\end{tabular} & 3.0835 \\
\hline & $1 / 800$ & 0.4137834 & 8.66232E-08 & - & 0.41378331 & 2.01280E-09 & - & 0.4137833044 & $2.24835 \mathrm{E}-10$ & - \\
\hline & $1 / 1600$ & 0.4137833 & - & - & 0.41378330 & - & - & 0.4137833042 & - & - \\
\hline \multirow{5}{*}{$\phi(0.25,0)$} & $1 / 100$ & 0.3973398 & $5.22660 \mathrm{E}-06$ & 1.8732 & 0.397332849 & 1.67992E-07 & 1.9964 & 0.3973326779 & 4.01044E-08 & 2.0026 \\
\hline & $1 / 200$ & 0.3973346 & $1.42667 \mathrm{E}-06$ & 1.8831 & 0.397332681 & 4.21036E-08 & 1.9918 & 0.3973326377 & $1.00080 \mathrm{E}-08$ & 2.0514 \\
\hline & $1 / 400$ & 0.3973332 & $3.86767 \mathrm{E}-07$ & 1.8917 & 0.397332638 & $1.05856 \mathrm{E}-08$ & 2.0538 & 0.3973326277 & $2.41450 \mathrm{E}-09$ & 2.7983 \\
\hline & $1 / 800$ & 0.3973328 & $1.04231 \mathrm{E}-07$ & - & 0.397332628 & 2.54962E-09 & - & 0.3973326253 & 3.47092E-10 & - \\
\hline & $1 / 1600$ & 0.3973327 & - & - & 0.397332625 & - & - & 0.3973326250 & - & - \\
\hline \multirow{5}{*}{$\phi(0.5,0)$} & $1 / 100$ & 0.3098369 & 9.79922E-06 & 1.7146 & 0.3098239 & 7.47130E-07 & 1.8649 & 0.309823112 & 2.00799E-07 & 1.8804 \\
\hline & $1 / 200$ & 0.3098271 & $2.98578 \mathrm{E}-06$ & 1.7403 & 0.3098231 & 2.05119E-07 & 1.8745 & 0.309822912 & 5.45398E-08 & 1.8982 \\
\hline & $1 / 400$ & 0.3098241 & 8.93639E-07 & 1.7618 & 0.3098229 & 5.59391E-08 & 1.9068 & 0.309822857 & $1.46323 \mathrm{E}-08$ & 2.0020 \\
\hline & $1 / 800$ & 0.3098232 & $2.63507 \mathrm{E}-07$ & - & 0.3098229 & 1.49183E-08 & - & 0.309822842 & 3.65311E-09 & - \\
\hline & $1 / 1600$ & 0.3098229 & - & - & 0.3098228 & - & - & 0.309822839 & - & - \\
\hline \multirow{5}{*}{$\phi(1,0)$} & $1 / 100$ & 0.1938271 & 4.14280E-06 & 1.8211 & 0.19382163 & $1.91348 \mathrm{E}-07$ & 1.9992 & 0.193821434 & 4.55464E-08 & 2.0024 \\
\hline & $1 / 200$ & 0.1938230 & 1.17242E-06 & 1.8407 & 0.19382144 & 4.78630E-08 & 1.9884 & 0.193821389 & $1.13676 \mathrm{E}-08$ & 2.0519 \\
\hline & $1 / 400$ & 0.1938218 & $3.27314 \mathrm{E}-07$ & 1.8564 & 0.19382139 & 1.20623E-08 & 2.3526 & 0.193821377 & 2.74145E-09 & 2.8430 \\
\hline & $1 / 800$ & 0.1938215 & 9.03931E-08 & - & 0.19382138 & 2.36166E-09 & - & 0.193821375 & 3.82071E-10 & - \\
\hline & $1 / 1600$ & 0.1938214 & - & - & 0.19382137 & - & - & 0.193821374 & - & - \\
\hline \multirow{5}{*}{$\begin{array}{c}\text { Average } \\
\text { current density } \\
\text { at } Y=0 \\
\frac{1}{0.5} \int_{X=0}^{X=0.5} \frac{\partial \phi}{\partial Y} d X\end{array}$} & $1 / 100$ & -0.600 & $5.39258 \mathrm{E}-03$ & 0.8100 & -0.6106 & 8.71790E-04 & 0.9952 & -0.61162 & 3.59484E-04 & 0.9990 \\
\hline & $1 / 200$ & -0.605 & $3.07586 \mathrm{E}-03$ & 0.8319 & -0.6115 & 4.37341E-04 & 0.9972 & -0.61198 & $1.79862 \mathrm{E}-04$ & 0.9995 \\
\hline & $1 / 400$ & -0.609 & $1.72796 \mathrm{E}-03$ & 0.8494 & -0.6119 & 2.19091E-04 & 0.9984 & -0.61216 & 8.99612E-05 & 0.9998 \\
\hline & $1 / 800$ & -0.610 & 9.59063E-04 & - & -0.6121 & $1.09665 \mathrm{E}-04$ & - & -0.61225 & $4.49880 \mathrm{E}-05$ & - \\
\hline & $1 / 1600$ & -0.611 & - & - & -0.6122 & - & - & -0.61230 & - & - \\
\hline
\end{tabular}


Observations from Table 2 are

- Unlike the primary current distribution, the secondary current distribution benefited from higher order methods. When high numerical accuracy is desired $\left(\mathrm{E}_{\mathrm{r}} \leq 1 \mathrm{E}-8\right)$, bicubic shape functions are found to be only marginally better than the biquadratic shape functions.

- FEM solution converged very quickly to 6 to 8 digits after the decimal, but convergence was sluggish after that.

- As expected, the numerical accuracy is lower near the singular point, with improved accuracy away from the singularity. This model is expected to benefit from mesh adaptivity. $^{11}$

An approximate analytical solution in the form of an infinite series can be written as

$$
\phi=\mathrm{A}_{0}(1-\mathrm{Y})+\sum_{\mathrm{i}=1}^{\mathrm{n}} \mathrm{A}_{\mathrm{i}} \cos (\mathrm{i} \pi \mathrm{X}) \sinh (\mathrm{i} \pi(1-\mathrm{Y}))
$$

where the coefficients are calculated using the boundary condition at $\mathrm{Y}=0$,

$$
\int_{X=0}^{X=1 / 2}\left(\left.\frac{\partial \phi}{\partial Y}\right|_{Y=0}-(\phi(X, 0)-1)\right) \cos (j \pi X) d X+\left.\int_{X=1 / 2}^{X=1} \frac{\partial \phi}{\partial Y}\right|_{Y=0} \cos (j \pi X) d X=0
$$

where $\mathrm{j}$ varies from 0 to $\mathrm{n}$. For this problem, there are two index counters ( $\mathrm{i}$ and $\mathrm{j}$ ) when calculating coefficients using Eq. (11) because the non-orthogonal terms (i.e. $\mathbf{i} \neq \mathbf{j}$ ) are nonzero for this problem. There would be only one index counter if only the orthogonal terms (i.e. $\mathbf{i}=\mathbf{j}$ ) were nonzero. This series solution converges to 6,8 , and 12 digits of accuracy with 5, 10, and 5000 terms, respectively (for $\phi$ at the anode).

These models become more complicated when additional physical phenomena are considered. Some of them are summarized in the subsequent sections. 


\section{Modifying the model for lithium metal battery architecture}

Under the same assumption of absence of concentration gradients, the steady-state model for the potential in the separator region with Butler-Volmer (BV) kinetics is given in Model 3.

\section{Model 3}

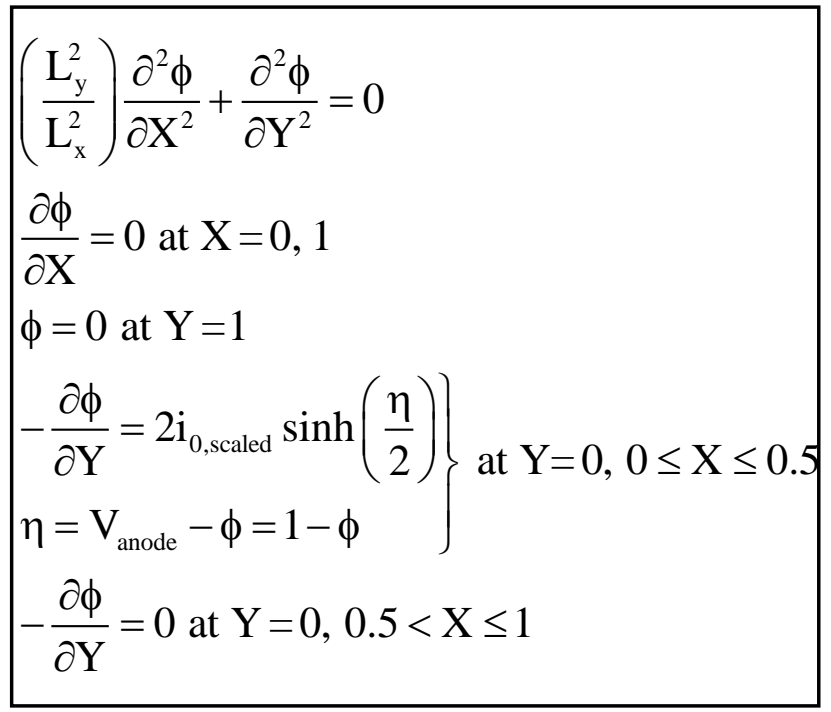

where $i_{0, \text { scaled }}$ is the nondimensional exchange current density defined as $i_{0, \text { scaled }}=\frac{i_{0} L_{y} F}{\kappa R T}$, and $L_{x}$ and $\mathrm{L}_{\mathrm{y}}$ are the height (or length) and thickness of the separator, respectively. The aspect ratio, defined as the ratio of $\mathrm{L}_{\mathrm{y}}$ and $\mathrm{L}_{\mathrm{x}}$, can be very high, very low, or close to 1 , depending on the original domain from the experiment or domain of interest (for microscale or pressure models).

We assume that the reaction has symmetric charge transfer coefficients, which allows the BV equation to be expressed in the form of hyperbolic sines. ${ }^{4} \mathrm{~V}_{\text {anode }}$ denotes the voltage of the anode which is specified to a fixed value, $\mathrm{V}_{\text {anode }}=1$. This value is used in the subsequent models wherever BV kinetics are considered.

The aforementioned discretization scheme (FEM) is applicable here, except for the nonlinearity occurring from the boundary condition at the anode, which is addressed using a Newton-Raphson (NR)-type iteration scheme. Typically, NR is iterated to much looser tolerance 
compared to machine precision (1E-8 or $1 \mathrm{E}-10$, for example). It should be noted that the error introduced by a NR-type iterative solver is in addition to the discretization error discussed earlier for the linear case in Model 2. Therefore, in addition to the discretization error, error and convergence analysis associated with the NR-type iterative solver should be reported wherever applicable. Also, using an NR-type iterative solver will make it computationally more challenging to use an extremely fine grid.

The challenges in simulation is the NR iteration coupled with singularity at the electrode/insulator interface.

\section{Time dynamics}

The Laplace's equation can provide the potential distribution in the separator region only in the absence of concentration gradients, and when there is a quasi-steady state. Typically, dynamics are important for the electrolyte distribution. There are mainly two different ways to model electrolyte transport dynamics, namely dilute and concentrated solution theories. ${ }^{4}$ With the electroneutrality and equal species diffusivity assumptions for a binary electrolyte, using dilute solution theory, the governing equations and boundary conditions are given by Model 4 . 
Model 4

$$
\begin{aligned}
& \frac{\partial \mathrm{c}}{\partial \tau}=\left(\frac{\mathrm{L}_{\mathrm{y}}^{2}}{\mathrm{~L}_{\mathrm{x}}^{2}}\right) \frac{\partial^{2} \mathrm{c}}{\partial \mathrm{X}^{2}}+\frac{\partial^{2} \mathrm{c}}{\partial \mathrm{Y}^{2}} \\
& \left(\frac{\mathrm{L}_{\mathrm{y}}^{2}}{\mathrm{~L}_{\mathrm{x}}^{2}}\right)\left(\mathrm{c} \frac{\partial^{2} \phi}{\partial \mathrm{X}^{2}}\right)+\mathrm{c} \frac{\partial^{2} \phi}{\partial \mathrm{Y}^{2}}+\left(\frac{\mathrm{L}_{\mathrm{y}}^{2}}{\mathrm{~L}_{\mathrm{x}}^{2}}\right)\left(\frac{\partial \phi}{\partial \mathrm{X}} \frac{\partial \mathrm{c}}{\partial \mathrm{X}}\right)+\frac{\partial \mathrm{c}}{\partial \mathrm{Y}} \frac{\partial \phi}{\partial \mathrm{Y}}=0
\end{aligned}
$$

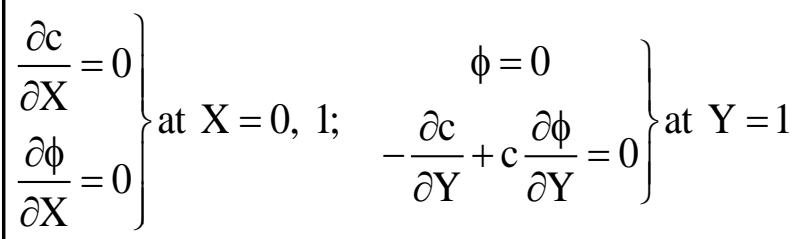

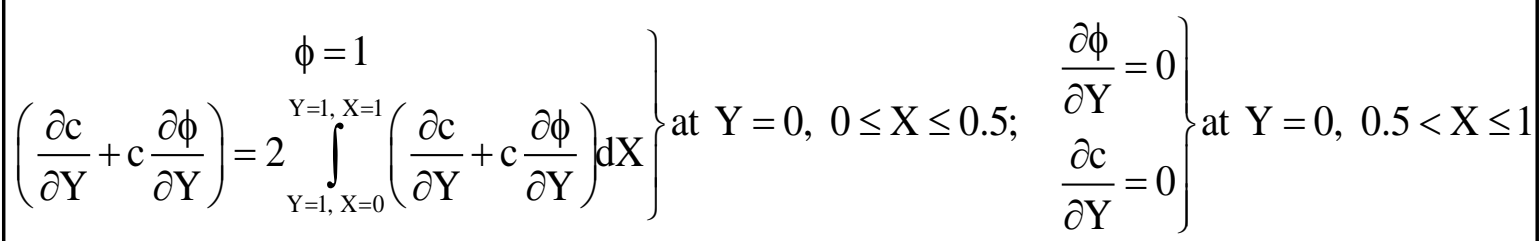

$$
\begin{aligned}
& \left.\begin{array}{l}
c=1 \\
\phi=0
\end{array}\right\} \text { for } X, Y \text { at } \tau=0
\end{aligned}
$$

At the electrode at $\mathrm{Y}=\mathbf{0}$, the cation flux is set to the average value at the top of the domain. The above flux condition may also be combined with the BV constitutive equation as done for Model 3.

At $\mathrm{Y}=1$, a zero-flux condition is imposed for the anion since it is assumed to be electrochemically inactive. Additionally, a fixed value of potential is specified to achieve problem closure.

This seemingly simple problem in the case of binary electrolyte can become challenging when solved in two dimensions for more than two species. From an error analysis point of view, an additional error arises from the use of time integrator in simulating this model. Based on the specified tolerance, the time-stepping for performing time-integration varies when using an adaptive solver in time to simulate this model. For a nonlinear problem, such as Model 3, the tolerance specified for the NR-type solver also influences the time-stepping to ensure that the solution obtained is within the tolerance for both the NR-type solver and the time-integrator. 
Additionally, as observed for Models 1 and 2, two-dimensional problems often involve solving a large number of equations which is challenging while performing time integration.

Computational challenges are the singularity at the electrode/insulator interface, aspect ratio (requiring approximate/representative region to be modeled with zero flux or periodic boundary conditions), degrees of freedom (DOF), nonlinearity in physical properties requiring NR at every time step for implicit ODE/DAE integration, and adaptive time stepping.

\section{Poisson Nernst Planck (PNP) model}

The electroneutrality assumption is not applicable for interfaces close to the electrodes. ${ }^{12}$ Even for a 1D problem, the PNP model is difficult to solve to high precision near the electrodes. ${ }^{13}$ This suggests that incorporating the PNP into 2D models with singularity in the domains of interest cannot be currently resolved to machine precision easily. A well-defined model with time dynamics and boundary conditions for the domain studied can be written in the scaled form as: 


$$
\begin{aligned}
& \frac{\partial \mathrm{C}}{\partial \tau}=\left(\frac{\mathrm{L}_{\mathrm{y}}^{2}}{\mathrm{~L}_{\mathrm{x}}^{2}}\right) \frac{\partial\left(\frac{\partial \mathrm{C}}{\partial \mathrm{X}}+\rho \frac{\partial \phi}{\partial \mathrm{X}}\right)}{\partial \mathrm{X}}+\frac{\partial\left(\frac{\partial \mathrm{C}}{\partial \mathrm{Y}}+\rho \frac{\partial \phi}{\partial \mathrm{Y}}\right)}{\partial \mathrm{Y}} \\
& \frac{\partial \rho}{\partial \tau}=\left(\frac{\mathrm{L}_{\mathrm{y}}^{2}}{\mathrm{~L}_{\mathrm{x}}^{2}}\right) \frac{\partial\left(\frac{\partial \rho}{\partial \mathrm{X}}+\mathrm{C} \frac{\partial \phi}{\partial \mathrm{X}}\right)}{\partial \mathrm{X}}+\frac{\partial\left(\frac{\partial \rho}{\partial \mathrm{Y}}+\mathrm{C} \frac{\partial \phi}{\partial \mathrm{Y}}\right)}{\partial \mathrm{Y}} \\
& \left(\frac{\mathrm{L}_{\mathrm{y}}^{2}}{\mathrm{~L}_{\mathrm{x}}^{2}}\right) \frac{\partial^{2} \phi}{\partial \mathrm{Y}^{2}}+\frac{\partial^{2} \phi}{\partial \mathrm{Y}^{2}}=-\frac{\rho}{\varepsilon^{2}} \\
& \frac{\partial \mathrm{C}}{\partial \mathrm{X}}+\rho \frac{\partial \phi}{\partial \mathrm{X}}=0 \\
& \left.\frac{\partial \rho}{\partial X}+C \frac{\partial \phi}{\partial X}=0\right\} \text { at } X=0,1 \\
& \frac{\partial \phi}{\partial \mathrm{X}}=0 \\
& \left.-\left(\frac{\partial C}{\partial Y}+\rho \frac{\partial \phi}{\partial Y}\right)=i_{0, \text { scaled }} \sinh \left(\frac{\eta}{2}\right)\right) \\
& \left.-\left(\frac{\partial \rho}{\partial \mathrm{Y}}+\mathrm{C} \frac{\partial \phi}{\partial \mathrm{Y}}\right)=\mathrm{i}_{0, \text { scaled }} \sinh \left(\frac{\eta}{2}\right)\right\} \text { at } \mathrm{Y}=0,0 \leq \mathrm{X} \leq 0.5 \\
& \eta=\mathrm{V}_{\text {anode }}-\phi=1-\phi \\
& 1-\phi=-\delta \varepsilon \frac{\partial \phi}{\partial y} \\
& \frac{\partial \mathrm{C}}{\partial \mathrm{Y}}+\rho \frac{\partial \phi}{\partial \mathrm{Y}}=0 \\
& \left.\frac{\partial \rho}{\partial Y}+C \frac{\partial \phi}{\partial Y}=0\right\} \text { at } \mathrm{Y}=0,0.5<\mathrm{X} \leq 1 \\
& \frac{\partial \phi}{\partial Y}=0 \\
& \left(\frac{\partial \mathrm{C}}{\partial \mathrm{Y}}+\rho \frac{\partial \phi}{\partial \mathrm{Y}}\right)=\left(\frac{1}{2}\right)_{\mathrm{Y}=0, \mathrm{X}=0}^{\mathrm{Y}=0, \mathrm{X}=0.5}\left(\frac{\partial \mathrm{C}}{\partial \mathrm{Y}}+\rho \frac{\partial \phi}{\partial \mathrm{Y}}\right) \mathrm{dX} \\
& \left.\begin{array}{l}
\left(\frac{\partial \rho}{\partial Y}+C \frac{\partial \phi}{\partial Y}\right)=\left(\frac{1}{2}\right) \int_{Y=0, X=0}^{Y=0, X=0.5}\left(\frac{\partial \rho}{\partial Y}+C \frac{\partial \phi}{\partial Y}\right) d X \\
\phi=0
\end{array}\right\} \text { at } \mathrm{Y}=1 \\
& \mathrm{C}=1 \\
& \rho=0\} \text { for } X, Y \text { at } \tau=0 \\
& \phi=0
\end{aligned}
$$


where the dimensionless species concentrations, expressed in terms of 'average concentration' and 'net charge density', are given by

$$
\mathrm{C}=\frac{\mathrm{c}_{1}+\mathrm{c}_{2}}{2} ; \rho=\frac{\mathrm{c}_{1}-\mathrm{c}_{2}}{2}
$$

The Poisson's equation introduces a parameter $\varepsilon=\lambda_{\mathrm{D}} / \mathrm{L}_{\mathrm{y}}$, which is the ratio of the thickness of the electrical double layer to the characteristic length scale of the system.

At the electrodes, we assume that only the cations participate in Faradaic reactions, and the flux of the anions at the electrodes is zero. At the insulated portion, the conditions of zero flux and zero electric field are applied. Here, all kinetic terms are expressed in the scaled form as well. At $\mathrm{Y}=1$, the cation flux at the anode is equated to the average value at the boundary at the top of the domain, thereby assuming a uniform flux to obtain problem closure. The zero-flux condition for the electrochemically inactive anion is implicit in the boundary conditions for the quantities $\mathbf{C}$ and $\rho$. With the double layer structure included in the boundary conditions, for closure, we assume net electroneutrality in the computation domain at all times, which is reasonable for most practical cases with $\varepsilon<<1 .{ }^{14}$

The computational challenges are all of the challenges listed for Model 3, the boundary layer close to the electrode where electroneutrality is violated, and additional variables (high DOF) compared to dilute solution theory.

\section{Moving boundary}

The simple model for the potential in Model 3 can be modified to a moving boundary problem as solved earlier for the electrodeposition problem by Alkire et al. ${ }^{15}$ The problem statement is described as: 


$$
\begin{aligned}
& \left(\frac{\mathrm{L}_{\mathrm{y}}^{2}}{\mathrm{~L}_{\mathrm{x}}^{2}}\right) \frac{\partial^{2} \phi}{\partial \mathrm{X}^{2}}+\frac{\partial^{2} \phi}{\partial \mathrm{Y}^{2}}=0 \\
& \frac{\partial \phi}{\partial X}=0 \text { at } X=0,1 \\
& \phi=0 \text { at } \mathrm{Y}=1 \\
& \left.-\nabla \phi \cdot \mathrm{n}=2 \mathrm{i}_{0, \text { scaled }} \sinh \left(\frac{\eta}{2}\right)\right) \\
& -\frac{\partial \mathrm{s}}{\partial \tau}=2 \mathrm{i}_{0, \text { scaled }} \sinh \left(\frac{\eta}{2}\right) \\
& \eta=\mathrm{V}_{\text {anode }}-\phi=1-\phi \\
& \mathrm{n}=\mathrm{n}_{\mathrm{X}} \hat{\mathrm{i}}+\mathrm{n}_{\mathrm{Y}} \hat{\mathrm{j}} \\
& \left.\mathrm{n}_{\mathrm{X}}=-\frac{\left(\frac{\mathrm{L}_{\mathrm{y}}}{\mathrm{L}_{\mathrm{x}}}\right) \frac{\partial \mathrm{s}}{\partial \mathrm{X}}}{\sqrt{\left(\mathrm{L}_{\mathrm{y}}\right)^{2}(\partial \mathrm{s})^{2}}}\right\} \text { at } \mathrm{Y}=0,0 \leq \mathrm{X} \leq 0.5 \\
& \sqrt{1+\left(\frac{\mathrm{L}_{\mathrm{y}}}{\mathrm{L}_{\mathrm{x}}}\right)^{2}\left(\frac{\partial \mathrm{s}}{\partial \mathrm{X}}\right)^{2}} \\
& \mathrm{n}_{\mathrm{Y}}=\frac{1}{\sqrt{1+\left(\frac{\mathrm{L}_{\mathrm{y}}}{\mathrm{L}_{\mathrm{x}}}\right)^{2}\left(\frac{\partial \mathrm{s}}{\partial \mathrm{X}}\right)^{2}}} \\
& -\frac{\partial \mathrm{s}}{\partial \tau}=-\nabla \phi \cdot \mathrm{n}=0 \\
& n=n_{X} \hat{i}+n_{Y} \hat{j} \quad \text { at } Y=0,0.5<X \leq 1 \\
& \mathrm{n}_{\mathrm{X}}=0 \\
& \mathrm{n}_{\mathrm{Y}}=1 \\
& \mathrm{~s}(\mathrm{X})=0 \text { at } \tau=0 \\
& \phi=0 \text { for } \mathrm{X}, \mathrm{Y} \text { at } \tau=0
\end{aligned}
$$

where electrochemical reaction occurs at $\mathrm{Y}=0$ at $\tau=0$. The velocity of the moving boundary is related to the normal component of the local electrostatic potential gradient.

This well-defined problem can be used to march forward in time to see how the morphology changes with time. This front-capturing method involves re-meshing the domain of interest. Phasefield and level-set methods are alternatives that avoid remeshing when the boundary has moved. ${ }^{16,17,18}$ These methods retain the original domain of interest and modify the models to 
include a source term in the equation, which handles the transition from one phase to another. In addition, different transport properties (D) are used in different phases. A very simple way to demonstrate this approach is the 1D model.

\section{Model 7a}

$$
\begin{aligned}
& \frac{\partial c}{\partial \tau}=\frac{\partial^{2} c}{\partial X^{2}} \\
& \frac{\partial c}{\partial X}=\delta \text { at } X=0 \\
& c=1 \text { at } X=1 \\
& c=1 \text { at } \tau=0 \text { for all } X
\end{aligned}
$$

Applying a cell-centered finite difference scheme, Model $7 \boldsymbol{a}$ can be discretized as

$$
\begin{aligned}
& \frac{d c_{i}(\tau)}{d \tau}=\frac{c_{i+1}(\tau)-2 c_{i}(\tau)+c_{i-1}(\tau)}{h^{2}} \text { for } 1 \leq i \leq N \\
& c_{i}(0)=1 \\
& c_{1}(\tau)-c_{0}(\tau)=\delta h \\
& c_{N}(\tau)+c_{N+1}(\tau)=2
\end{aligned}
$$

This equation has no source term in the bulk for the PDE, with the inhomogeneity occurring from the boundary condition at $\mathrm{X}=0$.

This model can be modified by moving the inhomogeneous boundary condition to the bulk of governing equation as: 


\section{Model $7 b$}

$$
\begin{aligned}
& \frac{\partial c}{\partial \tau}=D \frac{\partial^{2} c}{\partial X^{2}}+R \\
& D=\left\{\begin{array}{cc}
0 & X=0 \\
1 & 0<X \leq 1
\end{array}\right. \\
& R=\left\{\begin{array}{cc}
-\frac{\delta}{h} & 0 \leq X<h \\
0 & h \leq X \leq 1
\end{array}\right.
\end{aligned}
$$

Both models result in the same equations to be solved for time integration. High values of $\delta$ typically require a small mesh size ( $h$ ). If $h$ is small, the reaction term $R$ becomes very high. When the boundary moves with time, the parameters $(D, R)$ and time stepping must be carefully handled.

All the methods are approximate at the moving interface, and more accurate away from the moving interface. ${ }^{18}$ For analytically defined moving boundaries, front-capturing methods are more accurate than front-tracking methods. If the moving boundaries are complicated and the numerical resolution is poor, front-tracking methods may be more convenient, but the potential efficiency gained from front-capturing methods can be significant. All the methods are likely to require very fine meshes close to the electrodes. ${ }^{18}$

Challenges in the simulation - Challenges in moving boundary treatment, remeshing for front capturing models, calculation of fluxes at the moving boundary, singularity at moving boundary, and parameters for approximating MB models with phase-field models.

\section{Microscale effects}

Newman's porous electrode theory models a porous electrode consisting of solid and liquid phase in an average sense. When detailed porous electrode models (p2D type) are developed for both solid and liquid phases, with no source terms and the y-direction averaged, the reaction at the solid-liquid interface becomes a source term. Detailed micro-scale electrode models can be more 
accurate, specifically due to their ability to correlate effective transport properties in $\mathrm{p} 2 \mathrm{D}$ type models with electrode morphology. ${ }^{19}$ Having such detailed microscale models with singularity at the electrode surfaces (or close to it) will make the computation extremely challenging, and a recent article suggests that FEM and FVM arrive at different values for effective property calculations from micro-scale models, suggesting that grid convergence (in particular to machine precision) is perhaps not possible. ${ }^{20}$ Phase-separation dynamics in electrode particles are yet another class of physics that result in numerical challenges..$^{21,22}$

We now present some examples.

\subsection{Pressure models - kinetics}

The simple 2D model for $\phi$ with kinetics can be coupled with detailed pressure models, typically for the purpose of modifying the kinetics at the surface of the electrode. ${ }^{23,24}$ For the aforementioned moving boundary model, the modified model with pressure distribution is now introduced. A well-defined continuum model for the current distribution and the motion of the deformed moving boundary is: 


$$
\begin{aligned}
& \left(\frac{\mathrm{L}_{\mathrm{y}}^{2}}{\mathrm{~L}_{\mathrm{x}}^{2}}\right) \frac{\partial^{2} \phi}{\partial \mathrm{X}^{2}}+\frac{\partial^{2} \phi}{\partial \mathrm{Y}^{2}}=0 \\
& \frac{\partial \phi}{\partial X}=0 \text { at } X=0,1 \\
& \phi=0 \text { at } \mathrm{Y}=1 \\
& -\nabla \phi \cdot \mathrm{n}=2 \mathrm{i}_{0, \mathrm{def}} \sinh \left(\frac{\eta}{2}\right) \\
& -\frac{\partial \mathrm{s}}{\partial \tau}=2 \mathrm{i}_{0, \mathrm{def}} \sinh \left(\frac{\eta}{2}\right) \\
& \eta=\mathrm{V}_{\text {anode }}-\phi=1-\phi \\
& \mathrm{i}_{0, \text { def }}=\mathrm{i}_{0, \text { scaled }} \mathrm{e}^{-\gamma \mathrm{P}} \\
& n=n_{X} \hat{i}+n_{Y} \hat{j} \\
& \mathrm{n}_{\mathrm{X}}=-\frac{\left(\frac{\mathrm{L}_{\mathrm{y}}}{\mathrm{L}_{\mathrm{x}}}\right) \frac{\partial \mathrm{s}_{\mathrm{def}}}{\partial \mathrm{X}}}{\sqrt{1+\left(\frac{\mathrm{L}_{\mathrm{y}}}{\mathrm{L}_{\mathrm{x}}}\right)^{2}\left(\frac{\partial \mathrm{s}_{\mathrm{def}}}{\partial \mathrm{X}}\right)^{2}}} \\
& \mathrm{n}_{\mathrm{Y}}=\frac{1}{\sqrt{1+\left(\frac{\mathrm{L}_{\mathrm{y}}}{\mathrm{L}_{\mathrm{x}}}\right)^{2}\left(\frac{\partial \mathrm{s}_{\text {def }}}{\partial \mathrm{X}}\right)^{2}}} \\
& -\frac{\partial \mathrm{s}}{\partial \tau}=-\nabla \phi \cdot \mathrm{n}=0 \\
& \mathrm{n}=\mathrm{n}_{\mathrm{X}} \hat{\mathrm{i}}+\mathrm{n}_{\mathrm{Y}} \hat{\mathrm{j}} \quad \text { at } \mathrm{Y}=0,0.5<\mathrm{X} \leq 1 \\
& \mathrm{n}_{\mathrm{X}}=0 \\
& \mathrm{n}_{\mathrm{Y}}=1 \\
& s(X)=0 \text { at } \tau=0 \\
& \phi=0 \text { for } \mathrm{X}, \mathrm{Y} \text { at } \tau=0
\end{aligned}
$$


At the electrode interface, we make the simplifying assumptions of purely vertical motion. Considering the equation for moving boundary velocity, we also obtain the normal resolution equations accounting for the deformed height of the interface, which are also given above.

The key modification to these equations is via the scaled exchange current density $\mathbf{i}_{0, \text { scaled }}$. The effect of mechanical deformation is to modify the local reaction constant,

$$
\begin{aligned}
& \mathrm{i}_{0, \text { def }}=\mathrm{i}_{0, \text { scaled }} \mathrm{e}^{-\beta \mathrm{P}} \\
& \beta=-\mathrm{G}_{\mathrm{s}} \varsigma \\
& \varsigma=\frac{\overline{\mathrm{V}_{\mathrm{Li}}}-\left(1-\mathrm{t}_{0}^{+}\right) \overline{\mathrm{V}_{\mathrm{LiX}}}}{4 \mathrm{RT}}
\end{aligned}
$$

where $\mathrm{P}$ denotes an appropriately scaled value of the hydrostatic pressure at the electrodeelectrolyte interface and $\beta$ is a dimensionless enhancement factor. This expression is based under the simplifying assumption that the shear components of the stresses at electrode-electrolyte interfaces may be neglected, which is reasonable for low elastic moduli separators, such as with liquid electrolytes. In addition, linear elasticity is assumed, which is reasonable for liquid electrolytes and moderate external pressures. The pressure equation is typically modeled at a smaller scale. The equations and boundary conditions, assuming purely vertical stresses and deformations, are described by 


\section{Model $8 b$}

$$
\begin{gathered}
\sigma_{\mathrm{Y}}(\mathrm{X}, \tau)=\mathrm{E}_{\mathrm{s}}\left(\mathrm{s}_{\mathrm{d}}(\mathrm{X}, \tau)\right) \\
\mathrm{s}_{\mathrm{d}}(\mathrm{X}, \tau)=\mathrm{s}_{\mathrm{def}}(\mathrm{X}, \tau)-\mathrm{s}_{\mathrm{avg}}(\tau) \\
\mathrm{s}_{\text {def }}(\mathrm{X}, \tau)=\mathrm{s}(\mathrm{X}, \tau)-\left(\frac{\sigma_{\mathrm{Y}}(\mathrm{X}, \tau)}{\mathrm{E}_{\mathrm{Li}}}\right) \\
\mathrm{s}_{\mathrm{avg}}(\tau)=\int_{\mathrm{X}=0}^{\mathrm{X}=0.5} \mathrm{~s}(\mathrm{X}, \tau) \mathrm{dX} \\
\mathrm{P}=\sigma_{\mathrm{Y}}(\mathrm{X}, \tau)-\mathrm{P}_{\mathrm{ext}, \mathrm{scaled}} \\
\mathrm{s}(\mathrm{X}, 0)=0 \\
\sigma_{\mathrm{Y}}(\mathrm{X}, 0)=0
\end{gathered}
$$

where additional parameters have been introduced corresponding to the elastic modulus of the deposited electrode $E_{\mathrm{Li}}$ and of the electrolyte $E_{s}$, and the scaled external pressure $P_{\text {ext. }}$ The externally applied pressure is scaled with $G_{\mathrm{s}}$ as $P_{\text {ext,scaled }}=\frac{P_{\text {ext }}}{G_{s}}$.

If the full domain is to be solved with both pressure and potential, the relevant problem formulation is 


$$
\begin{aligned}
& \left(\frac{\mathrm{L}_{\mathrm{y}}^{2}}{\mathrm{~L}_{\mathrm{x}}^{2}}\right) \frac{\partial^{2} \phi}{\partial \mathrm{X}^{2}}+\frac{\partial^{2} \phi}{\partial \mathrm{Y}^{2}}=0 \\
& \left(\frac{\partial^{2} \mathrm{u}_{\mathrm{x}, \mathrm{s}}}{\partial \mathrm{X}_{1}^{2}}\right)+\left(\frac{\mathrm{L}_{\mathrm{x}}^{2}}{\mathrm{~L}_{\mathrm{y}}^{2}}\right)\left(\frac{\partial^{2} \mathrm{u}_{\mathrm{x}, \mathrm{s}}}{\partial \mathrm{Y}_{1}^{2}}\right)+\left(\frac{1}{1-2 \mathrm{v}_{\mathrm{s}}}\right)\left(\frac{\partial^{2} \mathrm{u}_{\mathrm{x}, \mathrm{s}}}{\partial \mathrm{X}_{1}{ }^{2}}+\frac{\partial^{2} \mathrm{u}_{\mathrm{y}, \mathrm{s}}}{\partial \mathrm{X}_{1} \partial \mathrm{Y}_{1}}\right)=0 \\
& \left(\frac{\mathrm{L}_{\mathrm{y}}^{2}}{\mathrm{~L}_{\mathrm{x}}^{2}}\right)\left(\frac{\partial^{2} \mathrm{u}_{\mathrm{y}, \mathrm{s}}}{\partial \mathrm{X}_{1}^{2}}\right)+\left(\frac{\partial^{2} \mathrm{u}_{\mathrm{y}, \mathrm{s}}}{\partial \mathrm{Y}_{1}^{2}}\right)+\left(\frac{1}{1-2 \mathrm{v}_{\mathrm{s}}}\right)\left(\frac{\partial^{2} \mathrm{u}_{\mathrm{y}, \mathrm{s}}}{\partial \mathrm{Y}_{1}^{2}}+\frac{\partial^{2} \mathrm{u}_{\mathrm{x}, \mathrm{s}}}{\partial \mathrm{X}_{1} \partial \mathrm{Y}_{1}}\right)=0 \\
& \left.\frac{\partial \phi}{\partial \mathrm{X}_{1}}=0 ; \mathrm{u}_{\mathrm{x}, \mathrm{s}}=0 ; \mathrm{u}_{\mathrm{y}, \mathrm{s}}=0\right\} \text { at } \mathrm{X}_{1}=0,1 \\
& \left.\frac{\partial \phi}{\partial Y_{1}}=0 ; u_{x, s}=0 ; u_{y, s}=0\right\} \text { at } Y_{1}=0,0.5<X_{1} \leq 1 \\
& \left.\phi=0 ; u_{\mathrm{x}, \mathrm{s}}=0 ; 2 \frac{\partial \mathrm{u}_{\mathrm{y}, \mathrm{s}}}{\partial \mathrm{Y}_{\mathrm{j}}}+\frac{2 \mathrm{v}_{\mathrm{s}}}{1-2 \mathrm{v}_{\mathrm{s}}}\left(\frac{\partial \mathrm{u}_{\mathrm{x}, \mathrm{s}}}{\partial \mathrm{X}_{\mathrm{j}}}+\frac{\partial \mathrm{u}_{\mathrm{y}, \mathrm{s}}}{\partial \mathrm{Y}_{\mathrm{j}}}\right)=\mathrm{P}_{\text {ext, scaled }}\right\} \text { at } \mathrm{Y}_{1}=1 \\
& \left(\sigma_{11, \mathrm{~s}} \mathrm{n}_{\mathrm{X}}+\sigma_{12, \mathrm{~s}} \mathrm{n}_{\mathrm{X}}-\left(\frac{\mathrm{G}_{\mathrm{Li}}}{\mathrm{G}_{\mathrm{s}}}\right) \sigma_{11, \mathrm{Li}} \mathrm{n}_{\mathrm{X}}-\left(\frac{\mathrm{G}_{\mathrm{Li}}}{\mathrm{G}_{\mathrm{s}}}\right) \sigma_{12, \mathrm{Li}} \mathrm{n}_{\mathrm{X}}\right)=0 \\
& \left(\sigma_{22, \mathrm{~s}} \mathrm{n}_{\mathrm{Y}}+\sigma_{21, \mathrm{~s}} \mathrm{n}_{\mathrm{Y}}-\left(\frac{\mathrm{G}_{\mathrm{Li}}}{\mathrm{G}_{\mathrm{s}}}\right) \sigma_{22, \mathrm{Li}} \mathrm{n}_{\mathrm{Y}}-\left(\frac{\mathrm{G}_{\mathrm{Li}}}{\mathrm{G}_{\mathrm{s}}}\right) \sigma_{21, \mathrm{Li}} \mathrm{n}_{\mathrm{Y}}\right)=0 \\
& \sigma_{11, i}=2 \frac{\partial u_{x, i}}{\partial X_{j}}+\frac{2 v_{i}}{1-2 v_{i}}\left(\frac{\partial u_{x, i}}{\partial X_{j}}+\frac{\partial u_{y, i}}{\partial Y_{j}}\right) \\
& \sigma_{22, \mathrm{i}}=2 \frac{\partial \mathrm{u}_{\mathrm{y}, \mathrm{i}}}{\partial \mathrm{Y}_{\mathrm{j}}}+\frac{2 \mathrm{v}_{\mathrm{i}}}{1-2 \mathrm{v}_{\mathrm{i}}}\left(\frac{\partial \mathrm{u}_{\mathrm{x}, \mathrm{i}}}{\partial \mathrm{X}_{\mathrm{j}}}+\frac{\partial \mathrm{u}_{\mathrm{y}, \mathrm{i}}}{\partial \mathrm{Y}_{\mathrm{j}}}\right) \\
& \sigma_{12, \mathrm{i}}=\sigma_{21, \mathrm{i}}=\left(\frac{\partial \mathrm{u}_{\mathrm{x}, \mathrm{i}}}{\partial \mathrm{Y}_{\mathrm{j}}}+\frac{\partial \mathrm{u}_{\mathrm{y}, \mathrm{i}}}{\partial \mathrm{X}_{\mathrm{j}}}\right) \\
& \mathrm{P}=-\left(\sigma_{11, \mathrm{~s}} \mathrm{n}_{\mathrm{X}}^{2}+\sigma_{12, \mathrm{~s}} \mathrm{n}_{\mathrm{X}} \mathrm{n}_{\mathrm{Y}}\right)-\left(\frac{\mathrm{G}_{\mathrm{Li}}}{\mathrm{G}_{\mathrm{s}}}\right)\left(+\sigma_{11, \mathrm{Li}} \mathrm{n}_{\mathrm{X}}^{2}+\sigma_{12, \mathrm{Li}} \mathrm{n}_{\mathrm{X}} \mathrm{n}_{\mathrm{Y}}\right)- \\
& \left(\frac{\mathrm{G}_{\mathrm{Li}}}{\mathrm{G}_{\mathrm{s}}}\right)\left(\sigma_{22, \mathrm{Li}} \mathrm{n}_{\mathrm{Y}}^{2}+\sigma_{21, \mathrm{Li}} \mathrm{n}_{\mathrm{X}} \mathrm{n}_{\mathrm{Y}}\right)-\left(\sigma_{22, \mathrm{~s}} \mathrm{n}_{\mathrm{Y}}^{2}+\sigma_{21, \mathrm{~s}} \mathrm{n}_{\mathrm{X}} \mathrm{n}_{\mathrm{Y}}\right) \\
& \text { at } \mathrm{Y}_{1}=0,0 \leq \mathrm{X}_{1} \leq 0.5 \\
& \mathrm{i} \in\{\mathrm{s}, \mathrm{Li}\} \\
& \mathrm{j} \in\{1,2\}
\end{aligned}
$$

The moving boundary equations are specified as a separate sub-model: 


\section{Model $9 b$}

$$
\begin{aligned}
& \frac{\partial \mathrm{s}_{\mathrm{x}}}{\partial \tau}=-2\left(\frac{\mathrm{L}_{\mathrm{y}}}{\mathrm{L}_{\mathrm{x}}}\right) \mathrm{i}_{0, \text { def }} \sinh \left(\frac{\eta}{2}\right) \mathrm{n}_{\mathrm{X}} ; \quad \frac{\partial \mathrm{s}_{\mathrm{y}}}{\partial \tau}=-2 \mathrm{i}_{0, \text { def }} \sinh \left(\frac{\eta}{2}\right) \mathrm{n}_{\mathrm{Y}} \\
& \mathrm{n}_{\mathrm{X}}=-\frac{\left(\frac{\mathrm{L}_{\mathrm{y}}}{\mathrm{L}_{\mathrm{x}}}\right) \frac{\partial \mathrm{s}_{\mathrm{y}}}{\partial \mathrm{X}_{1}}+\left(\frac{\mathrm{L}_{\mathrm{y}}}{\mathrm{L}_{\mathrm{x}}}\right) \frac{\partial \mathrm{u}_{\mathrm{y}, \mathrm{s}}}{\partial \mathrm{X}_{1}}}{\sqrt{\left(1+\frac{\partial \mathrm{s}_{\mathrm{x}}}{\partial \mathrm{X}_{1}}+\frac{\partial \mathrm{u}_{\mathrm{x}, \mathrm{s}}}{\partial \mathrm{X}_{1}}\right)^{2}+\left(\left(\frac{\mathrm{L}_{\mathrm{y}}}{\mathrm{L}_{\mathrm{x}}}\right) \frac{\partial \mathrm{s}_{\mathrm{y}}}{\partial \mathrm{X}_{1}}+\left(\frac{\mathrm{L}_{\mathrm{y}}}{\mathrm{L}_{\mathrm{x}}}\right) \frac{\partial \mathrm{u}_{\mathrm{y}, \mathrm{s}}}{\partial \mathrm{X}_{1}}\right)^{2}}} ; \\
& 1+\frac{\partial \mathrm{s}_{\mathrm{x}}}{\partial \mathrm{X}_{1}}+\frac{\partial \mathrm{u}_{\mathrm{x}, \mathrm{s}}}{\partial \mathrm{X}_{1}} \\
& \mathrm{n}_{\mathrm{Y}}=\frac{\sqrt{\left(1+\frac{\partial \mathrm{s}_{\mathrm{x}}}{\partial \mathrm{X}_{1}}+\frac{\partial \mathrm{u}_{\mathrm{x}, \mathrm{s}}}{\partial \mathrm{X}_{1}}\right)^{2}+\left(\left(\frac{\mathrm{L}_{\mathrm{y}}}{\mathrm{L}_{\mathrm{x}}}\right) \frac{\partial \mathrm{s}_{\mathrm{y}}}{\partial \mathrm{X}_{1}}+\left(\frac{\mathrm{L}_{\mathrm{y}}}{\mathrm{L}_{\mathrm{x}}}\right) \frac{\partial \mathrm{u}_{\mathrm{y}, \mathrm{s}}}{\partial \mathrm{X}_{1}}\right)^{2}}}{\sqrt{\left(\mathrm{C}^{2}\right.}} \\
& \eta=\mathrm{V}_{\text {anode }}-\phi=1-\phi \\
& \text { at } Y_{1}=0,0 \leq X_{1} \leq 0.5
\end{aligned}
$$

where $\mathrm{u}_{\mathrm{x}, \mathrm{s}}$ and $\mathrm{u}_{\mathrm{y}, \mathrm{s}}$ are the scaled $\mathrm{x}$ and $\mathrm{y}$-components of the displacement, respectively. The scaled exchange current density $\mathbf{i}_{0 \text {,scaled }}$ is modified as given by Eq. (21).

Further, the deposited metal also deforms according to linear elasticity. The metal domain is scaled with the same scaling factors as for the separator domain, for convenience. Additionally, these equations are solved in a different coordinate system from the electrolyte domain. Appropriate force balance conditions are specified, which establish the coupling between the two models. The deformation of the Li metal is given by Model $9 \boldsymbol{c}$.

\section{Model 9c}

$$
\begin{aligned}
& \left(\frac{\partial^{2} \mathrm{u}_{\mathrm{x}, \mathrm{Li}}}{\partial \mathrm{X}_{2}^{2}}\right)+\left(\frac{\mathrm{L}_{\mathrm{x}}^{2}}{\mathrm{~L}_{\mathrm{y}}^{2}}\right)\left(\frac{\partial^{2} \mathrm{u}_{\mathrm{x}, \mathrm{Li}}}{\partial \mathrm{Y}_{2}^{2}}\right)+\left(\frac{1}{1-2 \mathrm{v}_{\mathrm{Li}}}\right)\left(\frac{\partial^{2} \mathrm{u}_{\mathrm{x}, \mathrm{Li}}}{\partial \mathrm{X}_{2}^{2}}+\frac{\partial^{2} \mathrm{u}_{\mathrm{y}, \mathrm{Li}}}{\partial \mathrm{X}_{2} \partial \mathrm{Y}_{2}}\right)=0 \\
& \left(\frac{\mathrm{L}_{\mathrm{y}}^{2}}{\mathrm{~L}_{\mathrm{x}}^{2}}\right)\left(\frac{\partial^{2} \mathrm{u}_{\mathrm{y}, \mathrm{Li}}}{\partial \mathrm{X}_{2}^{2}}\right)+\left(\frac{\partial^{2} \mathrm{u}_{\mathrm{y}, \mathrm{Li}}}{\partial \mathrm{Y}_{2}^{2}}\right)+\left(\frac{1}{1-2 \mathrm{v}_{\mathrm{Li}}}\right)\left(\frac{\partial^{2} \mathrm{u}_{\mathrm{y}, \mathrm{Li}}}{\partial \mathrm{Y}_{2}^{2}}+\frac{\partial^{2} \mathrm{u}_{\mathrm{x}, \mathrm{Li}}}{\partial \mathrm{X}_{2} \partial \mathrm{Y}_{2}}\right)=0 \\
& \mathrm{u}_{\mathrm{x}, \mathrm{Li}}=0 ; \mathrm{u}_{\mathrm{y}, \mathrm{s}}=0 \text { at } \mathrm{X}_{2}=1 \\
& \mathrm{u}_{\mathrm{x}, \mathrm{Li}}=\mathrm{u}_{\mathrm{x}, \mathrm{s}} ; \mathrm{u}_{\mathrm{y}, \mathrm{Li}}=\mathrm{u}_{\mathrm{y}, \mathrm{s}} \text { at } \mathrm{Y}_{2}=0,0 \leq \mathrm{X}_{2} \leq 0.5 \\
& \mathrm{u}_{\mathrm{x}, \mathrm{Li}}=0 ; \mathrm{u}_{\mathrm{y}, \mathrm{Li}}=0 \text { at } \mathrm{Y}_{2}=-\mathrm{s}_{\mathrm{y}}, 0 \leq \mathrm{X}_{2} \leq 0.5
\end{aligned}
$$


At the vertical interfaces and insulated portions, zero flux and zero displacement conditions can be reasonably applied. At the positive electrode interface, the local displacement is linked to the scaled external pressure. Mechanical equilibrium conditions are applied at the interface between the separator and deposited metal. For a well-defined numerical simulation, mechanical boundary conditions need to be specified at the base of the deposited metal. Constraints on motion are specified in the models above. An approximate illustration of this problem is depicted below in Figure 3.

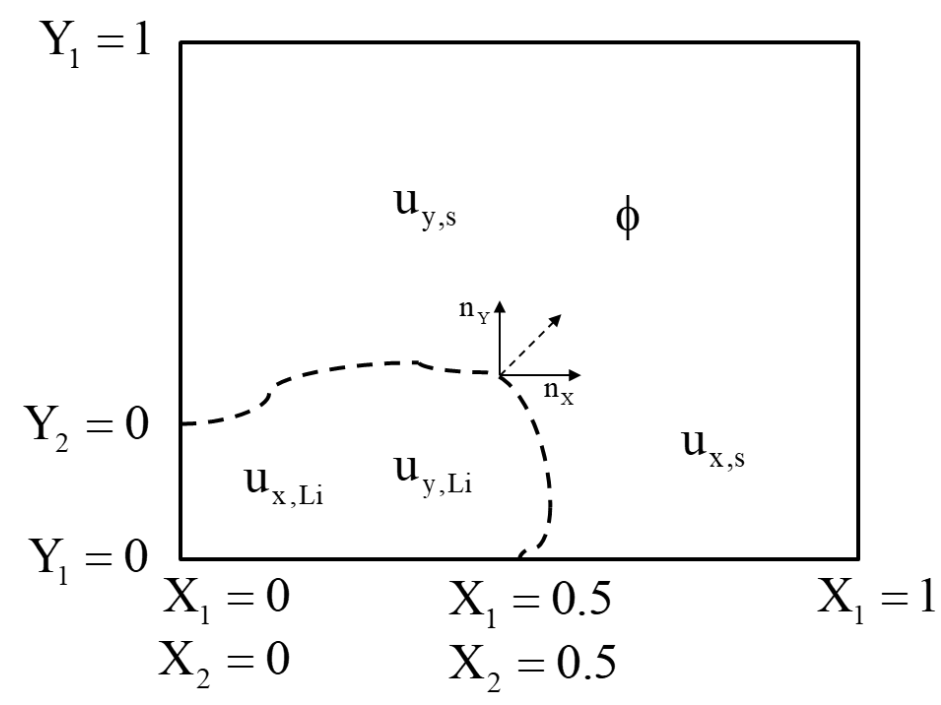

Figure 3. Representation of Model 9. The deformed state of the electrolyte and the deposited metal is depicted (dotted lines), although the model is solved in rectangular coordinate systems $\left(\mathrm{X}_{1}, \mathrm{Y}_{1}\right)$ and $\left(\mathrm{X}_{2}, \mathrm{Y}_{2}\right)$ for the electrolyte and metal, respectively.

The simulation challenges are all of the challenges listed for Models 3, 4, and 6, and coupled simultaneous simulation of moving boundary model and pressure/mechanical model.

\subsection{Porous electrodes - Tortuosity}

Assuming that the solid particles are perfect spheres, simplified spatially resolved micro-scale model equations for the electrolyte and particle phases are given by Models $10 \boldsymbol{a}$ and $10 \boldsymbol{b}$, respectively. 


$$
\begin{aligned}
& \frac{\partial \mathrm{c}}{\partial \tau}=\left(\frac{\mathrm{L}_{\mathrm{y}}^{2}}{\mathrm{~L}_{\mathrm{x}}^{2}}\right) \frac{\partial^{2} \mathrm{c}}{\partial \mathrm{X}^{2}}+\frac{\partial^{2} \mathrm{c}}{\partial \mathrm{Y}^{2}} \\
& \left(\frac{\mathrm{L}_{\mathrm{y}}^{2}}{\mathrm{~L}_{\mathrm{x}}^{2}}\right)\left(\mathrm{c} \frac{\partial^{2} \phi}{\partial \mathrm{X}^{2}}\right)+\mathrm{c} \frac{\partial^{2} \phi}{\partial \mathrm{Y}^{2}}+\left(\frac{\mathrm{L}_{\mathrm{y}}^{2}}{\mathrm{~L}_{\mathrm{x}}^{2}}\right)\left(\frac{\partial \phi}{\partial \mathrm{X}} \frac{\partial \mathrm{c}}{\partial \mathrm{X}}\right)+\frac{\partial \mathrm{c}}{\partial \mathrm{Y}} \frac{\partial \phi}{\partial \mathrm{Y}}=0 \\
& \left.\begin{array}{l}
\frac{\partial c}{\partial X}=0 \\
\frac{\partial \phi}{\partial X}=0
\end{array}\right\} \text { at } X=0,1 \text { and } 0 \leq Y \leq 1 \\
& \left.\begin{array}{l}
\frac{\partial c}{\partial Y}=0 \\
\frac{\partial \phi}{\partial Y}=0
\end{array}\right\} \text { at } Y=1 \text { and } 0 \leq X \leq 1 \\
& \left.\begin{array}{l}
\frac{\partial c}{\partial \mathrm{Y}}=0 \\
\frac{\partial \phi}{\partial \mathrm{Y}}=0
\end{array}\right\} \text { at } \mathrm{Y}=0 \text { and } 0.5 \leq \mathrm{X} \leq 1 \\
& \left.\begin{array}{c}
-\left(\frac{\mathrm{Dc}_{0}}{\mathrm{~L}_{\mathrm{y}}}\right) \frac{\partial \mathrm{c}}{\partial \mathrm{Y}}-\left(\frac{\mathrm{Dcc}_{0}}{\mathrm{~L}_{\mathrm{y}}}\right) \frac{\partial \phi}{\partial \mathrm{Y}}=\frac{2 \mathrm{i}_{\text {tot }}}{\mathrm{FL}_{\mathrm{x}}} \\
\phi=0
\end{array}\right\} \text { at } \mathrm{Y}=0 \text { and } 0 \leq \mathrm{X} \leq 0.5
\end{aligned}
$$




$$
\begin{aligned}
& \frac{\partial \mathrm{c}_{\mathrm{s}, \mathrm{i}}}{\partial \tau}=\left(\frac{\mathrm{D}_{\mathrm{s}} \mathrm{L}_{\mathrm{y}}^{2}}{\mathrm{DR}_{\mathrm{p}}^{2}}\right) \frac{1}{\mathrm{R}^{2}} \frac{\partial}{\partial \mathrm{R}}\left(\mathrm{R}^{2} \frac{\partial \mathrm{c}_{\mathrm{s}, \mathrm{i}}}{\partial \mathrm{R}}\right) \\
& -\frac{\mathrm{D}_{\mathrm{s}}}{\mathrm{R}_{\mathrm{p}}} \frac{\partial \mathrm{c}_{\mathrm{s}, \mathrm{i}}}{\partial \mathrm{R}}=\frac{\mathrm{i}_{\mathrm{BV}, \text { surf }, \text { avg }}}{\mathrm{F}} \\
& \left.\mathrm{i}_{\mathrm{BV}, \text { surf }}=2 \mathrm{i}_{0, \text { ref }} \mathrm{c}^{0.5}\left(\mathrm{c}_{\mathrm{s}, \mathrm{i}}\right)^{0.5}\left(\mathrm{c}_{\mathrm{s}, \max }-\mathrm{c}_{\mathrm{s}, \mathrm{i}}\right)^{0.5} \sinh \left(\frac{\eta_{\mathrm{i}}}{2}\right)\right\} \text { at } \mathrm{R}=1 \text { and } 1 \leq \mathrm{i} \leq \mathrm{N}_{\mathrm{P}} \\
& \eta_{\mathrm{i}}=\phi_{\mathrm{s}}(\tau)-\phi-\mathrm{U}\left(\mathrm{c}_{\mathrm{s}, \mathrm{i}}\right) \\
& \mathrm{i}_{\mathrm{BV}, \text { surf ,avg,i }}=\frac{1}{2 \pi} \int_{\theta=0}^{\theta=2 \pi} \mathrm{i}_{\mathrm{BV}, \text { surf }}(\theta) \mathrm{d} \theta \\
& \frac{\partial \mathrm{c}_{\mathrm{s}, \mathrm{i}}}{\partial \mathrm{R}}=0 \text { at } \mathrm{R}=0 \text { and } 1 \leq \mathrm{i} \leq \mathrm{N}_{\mathrm{P}} \\
& -\frac{\mathrm{D}_{\mathrm{s}}}{\mathrm{R}_{\mathrm{p}}} \frac{\partial \mathrm{c}_{\mathrm{s}, \mathrm{i}}}{\partial \mathrm{R}}=\mathrm{N}_{+, \text {surf,avg }, \mathrm{i}} ; \mathrm{N}_{+, \text {surf }, \text { avg }, \mathrm{i}}=\frac{1}{2 \pi} \int_{\theta=0}^{\theta=2 \pi} \mathrm{N}_{+, \text {surf }, \mathrm{i}} \mathrm{d} \theta=-\frac{\mathrm{D}_{\mathrm{s}}}{\mathrm{R}_{\mathrm{p}}} \frac{\partial \mathrm{c}_{\mathrm{s}, \mathrm{i}}}{\partial \mathrm{R}} \\
& \left.\mathrm{N}_{+, \text {surf }}=\left(-\frac{\mathrm{Dc}_{0}}{\mathrm{~L}_{\mathrm{x}}}\right) \frac{\partial \mathrm{c}}{\partial \mathrm{X}} \mathrm{n}_{\mathrm{X}, \mathrm{i}}-\left(\frac{\mathrm{Dcc}_{0}}{\mathrm{~L}_{\mathrm{x}}}\right) \frac{\partial \phi}{\partial \mathrm{X}} \mathrm{n}_{\mathrm{X}, \mathrm{i}}-\left(\frac{\mathrm{Dc}_{0}}{\mathrm{~L}_{\mathrm{y}}}\right) \frac{\partial \mathrm{c}}{\partial \mathrm{Y}} \mathrm{n}_{\mathrm{Y}, \mathrm{i}}-\left(\frac{\mathrm{Dcc}_{0}}{\mathrm{~L}_{\mathrm{y}}}\right) \frac{\partial \phi}{\partial \mathrm{Y}} \mathrm{n}_{\mathrm{Y}, \mathrm{i}}\right)^{\text {at }} 1 \leq \mathrm{i} \leq \mathrm{N}_{\mathrm{P}} \\
& \left.\mathrm{i}_{2, \text { surf }, \mathrm{i}}=-\left(\frac{2 \mathrm{FDcc}_{0}}{\mathrm{~L}_{\mathrm{x}}}\right) \frac{\partial \phi}{\partial \mathrm{X}} \mathrm{n}_{\mathrm{X}, \mathrm{i}}-\left(\frac{2 \mathrm{FDcc}_{0}}{\mathrm{~L}_{\mathrm{y}}}\right) \frac{\partial \phi}{\partial \mathrm{Y}} \mathrm{n}_{\mathrm{Y}, \mathrm{i}}\right\} \text { at } 1 \leq \mathrm{i} \leq \mathrm{N}_{\mathrm{P}} \\
& \mathrm{i}_{2, \text { surf,avg,i }}=\mathrm{i}_{\mathrm{BV}, \text { surf ,avg }, \mathrm{i}}=\frac{1}{2 \pi} \int_{\theta=0}^{\theta=2 \pi} \mathrm{i}_{2, \text { surf }, \mathrm{i}} \mathrm{d} \theta \\
& \mathrm{X}=\mathrm{X}_{\mathrm{c}, \mathrm{i}}+\left(\frac{\mathrm{R}_{\mathrm{p}}}{\mathrm{L}_{\mathrm{x}}}\right) \cos (\theta) ; \quad \mathrm{Y}=\mathrm{Y}_{\mathrm{c}, \mathrm{i}}+\left(\frac{\mathrm{R}_{\mathrm{p}}}{\mathrm{L}_{\mathrm{y}}}\right) \sin (\theta) \\
& \mathrm{X}_{\mathrm{c}, \mathrm{i}}+\left(\frac{\mathrm{R}_{\mathrm{p}}}{\mathrm{L}_{\mathrm{x}}}\right) \cos (\theta) \\
& \mathrm{n}_{\mathrm{X}, \mathrm{i}}=\frac{\sqrt{\left(\mathrm{X}_{\mathrm{c}, \mathrm{i}}+\left(\frac{\mathrm{R}_{\mathrm{p}}}{\mathrm{L}_{\mathrm{x}}}\right) \cos (\theta)\right)^{2}+\left(\mathrm{Y}_{\mathrm{c}, \mathrm{i}}+\left(\frac{\mathrm{R}_{\mathrm{p}}}{\mathrm{L}_{\mathrm{y}}}\right) \sin (\theta)\right)^{2}}}{} \\
& \mathrm{n}_{\mathrm{Y}, \mathrm{i}}=\frac{\mathrm{Y}_{\mathrm{c}, \mathrm{i}}+\left(\frac{\mathrm{R}_{\mathrm{p}}}{\mathrm{L}_{\mathrm{y}}}\right) \sin (\theta)}{\sqrt{\left(\mathrm{X}_{\mathrm{c}, \mathrm{i}}+\left(\frac{\mathrm{R}_{\mathrm{p}}}{\mathrm{L}_{\mathrm{x}}}\right) \cos (\theta)\right)^{2}+\left(\mathrm{Y}_{\mathrm{c}, \mathrm{i}}+\left(\frac{\mathrm{R}_{\mathrm{p}}}{\mathrm{L}_{\mathrm{y}}}\right) \sin (\theta)\right)^{2}}} \\
& \mathrm{i}_{\text {tot }}=2 \pi \mathrm{R}_{\mathrm{p}} \sum_{\mathrm{i}=1}^{\mathrm{N}_{\mathrm{p}}} \mathrm{i}_{\mathrm{BV} \text {,surf, avg }, \mathrm{i}} ; \quad-\left.\left(\frac{\mathrm{L}_{\mathrm{x}} \mathrm{FDCc}_{0}}{\mathrm{~L}_{\mathrm{y}}}\right) \frac{\partial \phi}{\partial \mathrm{Y}}\right|_{\mathrm{Y}=0}=\mathrm{i}_{\text {tot }}
\end{aligned}
$$


where the subscript $\mathrm{i}$ is used to denote the $\mathrm{i}^{\text {th }}$ solid particle and $\mathrm{N}_{\mathrm{p}}$ denotes the total number of solid particles in the domain.

The two sub-models are coupled through the boundary conditions at the particle surfaces. For simplicity, the continuity boundary condition is not applied at each point along the particle surface; instead, all of the electrolyte phase variables are applied in an average sense along the particle circumference. A uniform solid-phase potential $\phi_{\mathrm{s}}(\tau)$ is also assumed for convenience.

Simulation challenges include all of the challenges listed for Models 3 and 4, having different parameters for different domains, the calculation of fluxes at the interface between two phases (solid/liquid), high DOF, and higher index DAEs.

\section{Simulation and numerical aspects}

This section briefly states the important numerical and simulation aspects relevant for solving the models described, and in general for battery models. Each of the topics can be a separate critical review by itself, and only few personal perspectives are mentioned here.

\subsection{Spatial discretization}

Only FEM is discussed in depth for Models 1 and 2 . Many spatial discretization methods exist, including finite difference methods (constant grid, variable grid, higher order), finite volume methods, spectral methods, and global and local FEM (strong form, weak form, orthogonal collocation). All these methods result in a system of algebraic equations for steady-state models, and a system of differential-algebraic equations (DAEs) for models with time dynamics. Additionally, Adaptive meshing can be used for the spatial discretization of the domain. Some of the key factors to consider when determining the best method for a particular problem are order of convergence, DOF, accuracy near singularities, accuracy in calculating the flux at the boundary, direction of fluxes (convection/advection), calculation of curvature, and ease of implementation. 
Some methods might be more suitable than others for certain problems. For example, the finite element method in its weak form only conserves flux globally and not locally, whereas the finite volume formulation ensures that the flux is conserved locally in each finite volume considered. Higher order methods work very well for elliptic PDEs with no singularities, but for highly convective PDEs, a lower order locally conservative finite volume method may be more directly applicable. The best choice for spatial discretization can be answered by performing grid convergence studies, plots to observe possible spurious oscillations caused by insufficient grids or wrong choice of methods, and check on mass/charge conservation.

\subsection{Linear Solver}

A linear solver plays a critical role in the simulation of battery models. Even for the simple linear problems (Models 1 and 2), direct sparse solvers can be used only up to $1000 \times 1000$ elements, after which multigrid iterative methods are more efficient, which require solving the model repeatedly with different element sizes. ${ }^{25}$ Gaussian elimination ${ }^{26}$ used in the early days is replaced by banded solvers ${ }^{27}$, particularly for one-dimensional PDEs. For 2D problems, banded solvers are not optimal, and sparse iterative and direct solvers ${ }^{28}$ are used. COMSOL Multiphysics recommends the use of sparse direct solvers only up to 500,000 DOFs. ${ }^{25}$ GMRES and iterative solvers are preferred for larger number of DOFs. For Krylov-type efficient iterative solvers, good preconditioners are needed. ${ }^{28}$ Often, knowing the physics of the problem and solving a simpler problem helps in identifying a good preconditioner. Implicit and stiff solvers in time require linear solvers and restrict the number of DOFs, affecting memory and computational performance. 2D steady-state models involve the application of linear solvers. Time-dependent models will involve the linear solver at every time step if stiff integrators are used in time. 


\subsection{Time-integrators}

Discretization of battery models results in stiff partial differential algebraic equations (PDAEs). Once the spatial discretization is chosen, the resulting set of DAEs can be integrated in time with adaptive solvers using Method of Lines (MOL). ${ }^{29}$ There are multiple variations, possibilities, and demands for these solvers. For example, Backward difference methods $(B D F)^{30,31,32}$, as implemented in DASPK and IDA, offer efficient simulation of index-1 DAE arising from PNP equations (Model 4). Model 3 is strictly an index-2 DAE (if electroneutrality is not used to eliminate one of the concentration variables), which is best solved using RADAU5, an implicit Runge-Kutta method ${ }^{33}$.

The root-finding mechanism in DASKR is a useful feature as it enables automated transitions between discrete changes in operations, e.g., charging the battery until $4.2 \mathrm{~V}$ at constant current and then suddenly switching to constant potential mode. Such systems are typically called hybrid simulation or mixed continuous-discrete simulation in the literature. DASSL does not have that automated state transition capability, but is faster for battery simulations in which the operations have no state transitions. Hence, the discrete state transitions should be implemented manually. DASSL does not have the computational overhead associated with the implementation of automated state transitions, making it faster than DASKR. Implementing an additional capability in software typically occurs at the cost of numerical efficiency, unless proper care is taken to modify a particular code to increase numerical accuracy or robustness for the particular system and situation at hand. Many problems can be solved in a method-of-lines framework, however, some problems benefit from different discretization approaches in time for different parts of the models (for example, implicit time stepping for diffusion terms and explicit time stepping for convective terms when solving convection-diffusion type equations). 
It should be noted that a particular spatial discretization approach providing a particular order of accuracy for steady-state models may not provide the same order of accuracy in a MOL framework. In addition, all the time-integrators will not provide the expected order of accuracy in temporal discretization for the numerical simulation of PDAEs, in particular close to the boundaries, which are of interest for battery models. For example, while BDF methods can integrate stiff DAEs, the same approach, when used for temporal discretization in a simultaneous approach framework, loses order of accuracy (and yields unstable results) even for simple ODEs. ${ }^{34}$

\subsection{Programming environment}

Implementation of a particular algorithm in $\mathrm{C}++, \mathrm{C}$, or FORTRAN is likely to be more efficient compared to implementation in user-friendly platforms such as Maple or MATLAB. However, the learning curve for beginners is steeper. The platform and software used have effects on computational efficiency of a particular algorithm. While $\mathrm{C}$ can be faster than MATLAB, the Alb command in MATLAB seems to be well optimized for large-scale systems compared to opensource linear solvers. While Maple seems to enable faster symbolic calculations, its linear solver is not competitive to MATLAB. Some of the robust linear solvers/DAE solvers have restrictive licenses.

\subsection{Boundary conditions}

When micro-scale models are used in the literature, it is a common practice to use a bulk condition for the electrolyte away from the domain of interest. A bulk flux condition is more appropriate as that will conserve mass. Some of the past work involves resolving the boundary layers by developing approximate boundary conditions. ${ }^{4,35}$ High rates typically mean non-uniform current distributions, and both macro- and micro-scale models should be ideally solved without approximations. Even for the standard p2D models, for galvanostatic conditions, specifying solidor liquid-phase potential to a particular value is required for the model to be well-posed for 
simulation. While the location for specifying the potential value is arbitrary, this has a subtle but important effect in optimizing simulation algorithms for robustness and efficiency depending on the discretization scheme used.

\subsection{Battery management system (BMS) and real-time control}

BMS has been identified as a critical area to improve performance of energy storage systems. ${ }^{36}$ Recently, detailed models have been solved in real-time for control and design purposes. 37,38,39,40,41,42,43,44 These works were built on decades of research from multiple teams applying best possible algorithms for discretization in $\mathrm{x}, \mathrm{t}$ and careful mathematical analysis to reduce the number of states. This progress was facilitated by (1) a detailed model and open-source code published in 1993 by Newman's group ${ }^{45}$, (2) multiple groups attempted to simulate the same model more efficiently by introducing different reformulation and model reduction approaches ${ }^{46,47}$ $, 48,49,50,51,52,53$, and (3) the battery community applied (1) and (2) for validating model predictions with experimental data for a wide range of applications, chemistries, and form-factors. ${ }^{54,55} \mathrm{~A}$ similar approach is possible for detailed 2D and micro-scale models but will probably require many additional mathematical techniques and validation. For example, for the secondary current distribution problem described earlier, moving to the conformed coordinate (as done for the primary current distribution) requires a modified boundary condition at the anode as $\frac{\mathrm{d} \phi}{\mathrm{dY}}=\mathrm{f}(\mathrm{w})(\phi-1)$, where $\mathrm{f}(\mathrm{w})$ is a function of the intermediate conformal mapping variable, which enables higher order of accuracy for FEM and any spatial discretization approach. Even simple parabolic polynomial approximation provides 3 degrees of accuracy for the current and potential distribution for this problem. Similarly, Richardson extrapolation can provide 6 digits of accuracy for Model 1 even with less than 300×300 elements. On the other hand, an approach based on theoretical order of convergence might provide meaningless results. 
Parameter estimation and system engineering approaches require fast, efficient, and robust simulation of models. Many of the transport and kinetic parameters in the battery models are nonlinear and strongly affect the performance of batteries. The two main optimization-based methods for estimation and control are simultaneous and sequential approaches. If the underlying numerical scheme is not accurate enough, any method used to estimate parameters or perform optimal control (Bayesian estimation, MCMC, offline and online optimal control, surrogate model development) will likely fail or provide sub-optimal results. Even a gain of $0.01 \%$ per cycle will have a significant impact on battery performance. Machine precision is not needed as instruments have error in measurement; however, efficient and robust simulation to arrive at a relative tolerance

of $1 \mathrm{E}-6$ for the variables (and sensitivities with respect to parameters) requires careful analysis of different algorithms. Speed is essential in optimization- and model-based BMS frameworks for batteries that require real-time simulations for more than 1000s of cycles with different possible operating protocols.

\section{Conclusions and future needs}

At first, two simple 2D models, for primary and secondary current distributions, are presented and solved using FEM. These simple models suggest the critical need for grid convergence analysis. These models were modified to incorporate additional mechanisms and physics. Detailed, stand-alone, and well-defined models are provided as examples for numerical analysts to benchmark accuracy, and computational efficiency. Our recommendations are

(1) Perform and provide rigorous grid convergence results and mention the precision obtained. This grid convergence exercise should be performed at multiple locations in the domain. Special attention should be paid to the boundaries with singular points.

(2) Use finer mesh near the singular points and coarser mesh away from the singular points. In addition, use lower order methods near the singular points and higher order methods elsewhere. 
(3) Ideally, solve any multiscale model at least with two different methods to make sure the results have converged at least qualitatively.

(4) Pay attention to every numerical detail for best possible efficiency and robustness - method for spatial discretization, method for time-integration, linear solver, method for Jacobian calculation, software and hardware environment, etc. The list of considerations is long, and answered best using the global objective in hand, e.g., does the potential (or fade, power etc.) predicted by the model match the experimental data?

(5) In experimental work, it is a common practice to calculate the error in a measurement by accounting for contributions from various sources of error. This error is typically depicted by error bars when reporting experimental data. Similar practices are needed for modeling studies on batteries. We strongly encourage careful calculation and analysis of the numerical error considering all different sources of error, explicitly providing these values, precisely defining the error calculated, and possibly providing details in a separate section. The error should be calculated with respect to an analytical solution wherever possible.

(6) We also encourage that simulation-based studies clearly provide the solver related information, such as type of linear solver used, solver settings used in NR-type solver, type of time integrator along with relevant settings, and specified tolerance for both the NR-type solver as well as time integrator.

A webpage with numerical methods and results for the models discussed in this paper will be maintained by the authors for continued repository and updates for different algorithms/models/codes for batteries. Webpage URL: http://sites.utexas.edu/maple/challengesin-moving-to-multiscale-battery-models-where-electrochemistry-meets-and-demands-morefrom-math/ 


\section{Acknowledgements}

The authors would like to thank the U.S. Department of Energy (DOE) for providing financial support for this work through Advanced Battery Material Research (BMR) Program (Battery 500 Consortium) and acknowledge partial support from UT energy institute. The authors would also like to acknowledge support from Accelerated Materials Discovery and Design Program of the Toyota Research Institute through the D3BATT center on Data-Driven Design of Rechargeable Batteries. VS would like to acknowledge Professor C. Ahmad Basha who taught the method of conformal mapping and its importance during his undergraduate studies. VS would like to acknowledge Professor John Newman for highlighting the importance of conformal mapping during an earlier publication as the ECS editor. ${ }^{56}$ In addition, VS would like to thank Dr. Leszek F. Demkowicz for directing us to special FEM methods for simulating singular elliptic PDEs efficiently. A presentation on results from Models 1 and 2 was provided by VS in Multiscale Simulation Symposium in honor of Professor Richard C. Alkire during the $235^{\text {th }}$ ECS meeting on May 25, 2019.

\section{References}

1. M. Tang, P. Albertus, and J. Newman, J. Electrochem. Soc., 156, A390 (2009).

2. K. N. Wood, E. Kazyak, A. F. Chadwick, K. H. Chen, J. G. Zhang, K. Thornton, and N. P. Dasgupta, ACS Cent. Sci., 2, 790 (2016).

3. G. Bieker, M. Winter, and P. Bieker, Phys. Chem. Chem. Phys., 17, 8670 (2015).

4. J. Newman and K. E. Thomas-Alyea, Electrochemical Systems, $3^{\text {rd }}$ ed., John Wiley and Sons, Inc., Hoboken, New Jersey (2004).

5. A. C. West and J. S. Newman, in Modern Aspects of Electrochemistry, Vol. 23, B. E. Conway, 
J. O’M. Bockris, and R. E. White, Editors, p. 113, Plenum Press, New York (1992).

6. G. Prentice, Electrochemical Engineering Principles, p. 195, Prentice Hall, Englewood Cliffs, NJ (1986).

7. V. R. Subramanian and R. E. White, J. Electrochem. Soc., 147, 1636 (2000).

8. I. Babuška, R. B. Kellogg, and J. Pitkäranta, Numer. Math., 33, 447 (1979).

9. H.F. Moulton, Proc. of the London Math. Soc., 2,104 (1905).

10. M. Z. Bazant and D. Crowdy, Conformal mapping methods for interfacial dynamics, in Handbook of Materials Modeling, ed. by S. Yip, Vol. I, Art. 4.10 (Springer, 2005).

11. W. F. Mitchell, Appl. Math. Comput., 220, 350 (2013).

12. M. Z. Bazant, K. Thornton, and A. Ajdari, Phys. Rev. E, 70, 24 (2004).

13. A. Subramaniam, J. Chen, T. Jang, N. R. Geise, R. M. Kasse, M. F. Toney, and V. R. Subramanian, J. Electrochem. Soc., 166, A3806 (2019).

14. A. Bonnefont, F. Argoul, and M. Z. Bazant, J. Electroanal. Chem., 500, 52 (2001).

15. R. Alkire, T. Bergh, and R. L. Sani, J. Electrochem. Soc., 125, 1981 (1978).

16. G. Caginalp, Arch. Ration. Mech. Anal., 92, 205 (1986).

17. S. Chen, B. Merriman, S. Osher, and P. Smereka, J. Comput. Phys., 135, 8 (1997).

18. S. Popinet and S. Zaleski, Int. J. Numer. Methods Fluids, 30, 775 (1999).

19. G. B. Less, J. H. Seo, S. Han, A. M. Sastry, J. Zausch, A. Latz, S. Schmidt, C. Wieser, D. Kehrwald, and S. Fell, J. Electrochem. Soc., 159, A697 (2012).

20. B. L. Trembacki, A. N. Mistry, D. R. Noble, M. E. Ferraro, P. P. Mukherjee, and S. A. Roberts, 
J. Electrochem. Soc., 165, E725 (2018).

21. Y. Zeng and M. Z. Bazant, SIAM J. Appl. Math., 74, 980 (2014).

22. Y. Zeng, P. Albertus, R. Klein, N. Chaturvedi, A. Kojic, M. Z. Bazant, and J. Christensen, J. Electrochem. Soc., 160, A1565 (2013).

23. A. Ferrese and J. Newman, J. Electrochem. Soc., 161, 1350 (2014).

24. C. Monroe and J. Newman, J. Electrochem. Soc., 152, A396 (2005).

25. V. Marra, COMSOL Blog, https://www.comsol.com/blogs/on-solvers-multigrid-methods/, last accessed: June 2020.

26. J.F. Grcar, Historia Mathematica, 38, 163 (2011).

27. L.H. Thomas, Watson Sci. Comput. Lab. Rept., Columbia University, New York, 1 (1949).

28. Y. Saad, Iterative Methods for Sparse Linear Systems, $2^{\text {nd }}$ ed., SIAM, Philadelphia (2003).

29. W. E. Schiesser, The Numerical Method of Lines: Integration of Partial Differential Equations, Academic Press Inc., San Diego (1991).

30. C.F. Curtiss and J.O. Hirschfelder, Proc. of the Nat. Academy of Sci. of the United States of America, 38, 235 (1952).

31. L. Petzold, SIAM J. on Scientific and Statistical Computing, 3, 367 (1982).

32. B. Gear. Scholarpedia, 2, 3162 (2007).

33. E. Hairer and G. Wanner, J. of Comp. and App. Math., 111, 93 (1982).

34. W. W. Hager, SIAM J. Numer. Anal., 13, 449 (1976).

35. L. H. Olesen, M. Z. Bazant, and H. Bruus, Phys. Rev. E., 82, 1 (2010). 
36. ARPA-E, https://arpa-e.energy.gov/?q=arpa-e-programs/amped, last accessed: June 2020.

37. V. Ramadesigan, P. W. C. Northrop, S. De, S. Santhanagopalan, R. D. Braatz, and V. R. Subramanian, J. Electrochem. Soc., 159, R31 (2012).

38. S. Kolluri, S. V. Aduru, M. Pathak, R. D. Braatz, and V. R. Subramanian, J. Electrochem. Soc., 167, 063505 (2020).

39. J. Liu, G. Li, and H. K. Fathy, IEEE Trans. Control Syst. Technol., 25, 1882 (2017).

40. M. Torchio, N. A. Wolff, D. M. Raimondo, L. Magni, U. Krewer, R. B. Gopaluni, J. A. Paulson, and R. D. Braatz, Proc. Am. Control Conf., 4536 (2015).

41. M. Torchio, L. Magni, R. D. Braatz, and D. M. Raimondo, J. Electrochem. Soc., 164, A949 (2017).

42. H. E. Perez, S. Dey, X. Hu, and S. J. Moura, J. Electrochem. Soc., 164, A1679 (2017).

43. A. Hoke, A. Brissette, D. Maksimović, A. Pratt, and K. Smith, IEEE Veh. Power and Propuls. Conf., 1 (2011).

44. C. Speltino, D. D. Domenico, G. Fiengo, and A. Stefanopoulou, Proc. IEEE Conf. Decis. Control, 3276 (2009).

45. M. Doyle, T. F. Fuller, and J. Newman, J. Electrochem. Soc., 140, 1526 (1993)

46. C. Y. Wang, W. B. Gu, and B. Y. Liaw, J. Electrochem. Soc., 145, 3407 (1998).

47. C. Y. Wang and V. Srinivasan, J. Power Sources, 110, 364 (2002).

48. V. R. Subramanian, D. Tapriyal, and R. E. White, Electrochem. Solid-State Lett., 7, A259 (2004).

49. S. Santhanagopalan, Q. Guo, P. Ramadass, and R. E. White, J. Power Sources, 156, 620 
(2006).

50. K. A. Smith, C. D. Rahn, and C. Y. Wang, J. Dyn. Syst. Meas. Control. Trans. ASME, 130, 011012 (2008)

51. L. Cai and R. E. White, J. Electrochem. Soc., 156, A154 (2009).

52. V. R. Subramanian, V. Boovaragavan, V. Ramadesigan, and M. Arabandi, J. Electrochem. Soc., 156, A260 (2009).

53. P. W. C. Northrop, V. Ramadesigan, S. De, and V. R. Subramanian, J. Electrochem. Soc., 158, A1461 (2011).

54. W. Fang, O. J. Kwon, and C. Y. Wang, Int. J. Energy Res., 34, 107 (2010).

55. Y. Ye, Y. Shi, N. Cai, J. Lee, and X. He, J. Power Sources, 199, 227 (2012).

56. V. R. Subramanian and R. E. White, J. Electrochem. Soc., 147, 1636 (2000). 